\title{
Ocean Mixed Layer Temperature Variations Induced by Intraseasonal Convective Perturbations over the Indian Ocean
}

\author{
JeAn Philippe Duvel and RÉmy RocA \\ Laboratoire de Météorologie Dynamique, Paris, France \\ JÉRÔME VIALARD \\ Laboratoire d'Océanographie Dynamique et de Climatologie, Paris, France
}

(Manuscript received 15 April 2003, in final form 19 November 2003)

\begin{abstract}
In situ and satellite observations reveal that the tropical intraseasonal oscillation is occasionally associated with large variations in sea surface temperature (SST). The purpose of this paper is to find the physical origin of such strong SST perturbations (up to $3 \mathrm{~K}$ ) over the Indian Ocean by examining two intraseasonal events in January and March 1999. Analysis of SST data from the Tropical Rainfall Measuring Mission (TRMM) Microwave Imager (TMI) and from drifting buoys reveals that these two intraseasonal events deeply modify the SST field between the equator and $10^{\circ} \mathrm{S}$, while the surface flux perturbation extends over a wide area of the tropical Indian Ocean. Forced ocean general circulation model (OGCM) simulations are successful in reproducing the spatial patterns of this intraseasonal SST variability albeit with a weaker amplitude. The weaker amplitude given by the OGCM is partly related to the absence of warm-layer formation in the model. The model simulation reveals that the background oceanic subsurface structure explains the observed latitudinal distribution of the SST perturbations. For the Indian Ocean, the Ekman pumping (reinforced in 1999 due to La Niña conditions) gives a thermocline close to the surface between $5^{\circ}$ and $10^{\circ} \mathrm{S}$ that inhibits the deepening of the mixed layer during strong wind episodes and thus gives a mixed layer temperature more reactive to surface forcing. Other factors like the Ekman dynamics associated with the wind burst and the precipitation perturbation south of the equator also contribute toward preventing the deepening of the mixed layer. For these regions, as is found over the western Pacific, the intraseasonal variability of the SST is mainly driven by the surface fluxes perturbation, and not by advection or exchanges with the subsurface. As a consequence, the phasing and the magnitude of convective and large-scale dynamical perturbations of the surface fluxes, which are regionally dependent, are also determinant factors for the local amplitude of the SST perturbation. Finally, results show a relation at interannual time scales between the thermocline structure and the mixed layer depth south of the equator that may have consequences on interannual changes in the intraseasonal activity over the Indian Ocean.
\end{abstract}

\section{Introduction}

The deep convective activity over the Indo-Pacific region is strongly modulated at time scales between 20 and 60 days. This intraseasonal variability (ISV) has a marked seasonal cycle with an eastward propagation of the convective perturbation close to the equator from the Indian to the western Pacific Oceans during the boreal winter. This phenomenon is generally referred to as the Madden-Julian oscillation (see Madden and Julian 1994 for a review) and may interact with El NiñoSouthern Oscillation (ENSO) (see McPhaden 1999; Zhang et al. 2001). During the boreal summer, the eastward propagation along the equator over the Indian

Corresponding author address: Jean Philippe Duvel, Laboratoire de Météorologie Dynamique, ENS-24, Rue Lhomond, 75231-Paris, Cedex 05, France.

E-mail: jpduvel@1md.ens.fr
Ocean is followed by a northward propagation of the convective perturbation from the equator into the Indian peninsula (see Lawrence and Webster 2002). These intraseasonal perturbations have an impact on the Indian monsoon and may even influence its seasonal mean and its interannual variability (Webster et al. 1998; Goswami and Mohan 2000). There is growing evidence from both model simulations and observations that air-sea interactions may play a large role in the generation and in the characteristics of the ISV of the convection.

In situ observations revealed strong ( $\sim 2 \mathrm{~K})$ SST modulation at intraseasonal time scales in relation with convective perturbations in the China Sea (Kawamura 1988) and in the Bay of Bengal (Sengupta and Ravichandran 2001). During the Tropical Ocean Global Atmosphere Coupled Ocean-Atmosphere Response Experiment (TOGA COARE), an intraseasonal modulation of the SST larger than $1 \mathrm{~K}$, with an additional diurnal variation larger than $1 \mathrm{~K}$ during warm episodes, was 
also observed over the intensive flux array (Weller and Anderson 1996; Anderson et al. 1996). Further analyses by Shinoda and Hendon $(1998,2001)$ show that this modulation of the SST over the western Pacific warm pool was mostly controlled by surface heat flux variations and that the diurnal variation increases the intraseasonal amplitude of the SST. However, statistical composite studies, using weekly SST analyses of Reynolds and Smith (1994), reveal a modest SST variability (a few tenths of a degree) related to the ISV of convective activity and surface fluxes (Jones et al. 1998; Shinoda et al. 1998; Woolnough et al. 2000). This small average SST perturbation is probably due first to a variable structure of the relation between the SST and the outgoing longwave radiation (OLR) perturbations for the different intraseasonal events. This may also be related to the lack of intraseasonal variability in the weekly SST analyses of Reynolds and Smith (1994) due to screening effect of the cloudiness in the SST estimate by satellite measurements in the infrared atmospheric window. Harrison and Vecchi (2001), using the Tropical Rainfall Measuring Mission (TRMM) Microwave Imager (TMI) measurements, have shown a very large modulation of the SST between $5^{\circ}$ and $10^{\circ} \mathrm{S}$ associated with a largescale perturbation of convective activity over the Indian Ocean. They suggested that this SST variability was linked to Ekman pumping of subsurface water in the surface layer. Sengupta et al. (2001), who also used the TMI dataset for three summers (1998-2000), have shown a coherent modulation of SST (larger than $2 \mathrm{~K}$ in the Bay of Bengal) and of surface heat fluxes corresponding to the northward propagation of the intraseasonal perturbation of the convection.

The role of air-sea interaction on the ISV of convection was first investigated using simplified or idealized aquaplanet models (Wang and Xie 1998; Woolnough et al. 2001). These studies show that the simulation of the eastward propagation of the intraseasonal convective perturbation is sensitive to air-sea coupling. The coupling between atmospheric GCMs, with a slab (Waliser et al. 1999), intermediate (Kemball-Cook et al. 2002), or full (Inness and Slingo 2003) ocean model, has also an important impact on the simulation of the eastward propagation during boreal winter and the northward propagation of convection during the Indian monsoon (Fu et al. 2003). Ocean GCMs forced with observed or analyzed (European Centre for MediumRange Weather Forecasts; ECMWF) surface atmospheric forcing are also able to reproduce realistic intraseasonal modulation of the SST (Shinoda and Hendon 2001; Schiller and Godfrey 2003).

Further studies are, however, still requested to better understand the physical mechanisms at the origin of the modulation of mixed layer and surface temperature, in particular for the winter south Indian Ocean where the TMI dataset has revealed strong and somewhat unexpected ISV of the SST. Seasonal and geographical variability of the ISV and the variability from one ISV event to another suggest that there is not a single type of air-sea interaction (phasing between the surface parameters and the convective perturbation) at this time scale (Hendon and Salby 1994; Zhang and McPhaden 2000). Many different physical mechanisms may be needed to explain such an interaction. First, the perturbation of convection associated with the ISV has a direct effect on the incident solar flux at the surface. The numerous mesoscale convective systems embedded in the ISV envelope, because of their associated local dynamical perturbation, also have a nonlinear impact on the surface turbulent fluxes (Redelsperger et al. 2000). The convectively active phase of the ISV is also associated with large-scale surface wind perturbations that may modify the SST through surface latent and sensible heat fluxes and through the perturbation of the ocean dynamics (horizontal advection, shear-generated turbulent mixing, Ekman pumping) by the surface wind stress. The impact of these flux perturbations on the SST will also obviously depend on the local average stratification of the ocean that will be considered in the present study. Among the different processes, the depth of the thermocline or the presence of a barrier layer (Lukas and Lindström 1991) may play a role in the response of the mixed layer temperature to atmospheric forcing (Shinoda and Hendon 1998; Schiller and Godfrey 2003). Beyond the potential air-sea coupling on an intraseasonnal time scale, it is also useful to understand if interannual variation of the thermal structure of the ocean can have an impact on the ISV characteristics. The knowledge of this structure could then be a useful element for forecasting the characteristics of the ISV for the coming season.

This article describes and analyzes in detail two ISV events during the boreal winter of 1998/99 for which there is a large intraseasonal perturbation of the SST above the Indian Ocean (Harrison and Vecchi 2001). Section 2 reports a summary of the various datasets and analysis methods, and describes the oceanic general circulation model (OGCM) used in this study. Section 3 presents the background atmospheric circulation in 1999 (La Niña year) and gives a synoptic description of the January and March 1999 intraseasonal events. An evaluation of satellite and reanalysis products, and of the OGCM used in this study, is presented in section 4. In section 5, we analyze the physical source of the strong SST intraseasonal perturbations using observations and forced simulations from the OGCM. Summary and discussion are reported in section 6 .

\section{Data, model, and analysis method}

\section{a. Datasets}

The National Oceanic and Atmospheric Administration's (NOAA) OLR dataset (Liebmann and Smith 
1996) gives a proxy to study the perturbation of the convective activity. The intraseasonal perturbation of the SST is examined using the TMI dataset (Wentz et al. 2000). The TMI instrument makes it possible to estimate the SST in cloudy conditions and is thus well adapted to study the link between convection and the SST. The orbital characteristics of TRMM, the swath of the TMI instrument, and missing SST estimates due to heavy rainfall however result in some data-void regions each day. To obtain a full tropical $\left(38.5^{\circ} \mathrm{N}, 38.5^{\circ} \mathrm{S}\right)$ daily coverage, we have performed an interpolation by doing spatial filling and linear temporal interpolation from daily mean fields containing all the orbits projected on a $1^{\circ} \times 1^{\circ}$ grid. The impact of the orbital crossing local time on the determination of the SST in a region of strong diurnal variation is discussed in section 4a.

The role of surface fluxes in the modulation of the SST is estimated using the analyses of the ECMWF. Due to uncertainties in the estimation of these quantities, especially for these ocean tropical regions with poor data coverage, the aim of this diagnostic is more to find qualitative arguments explaining the regional difference in the SST perturbation than to establish a robust quantitative estimate of these effects. The daily surface turbulent fluxes estimated from Special Sensor Microwave Imager (SSM/I) measurements (Chou et al. 1997) are also used. This alternative dataset also makes it possible to estimate the uncertainty on our knowledge of these turbulent fluxes.

In situ measurements made by isopycnal balloons (Ethé et al. 2002) during the Indian Ocean Experiment (INDOEX; Ramanathan et al. 2001) and by Surface Velocity Program (SVP) drifters (distributed by the NOAA/Atlantic Oceanographic and Meteorological Laboratory's Drifting Buoy Data Assembly Center, Miami, Florida) are also used to evaluate, respectively, the ECMWF low-level dynamical field south of the equator and the TMI SST variability.

\section{b. Detection and characterization of the two convective ISV events}

The ISV mode structure of the convective perturbation is determined using a local mode analysis (LMA; Goulet and Duvel 2000) of the NOAA OLR dataset. We use this technique because the spatial structure of the ISV of convection is quite variable from one event to another. The study of the ISV characteristics thus necessitates locating precisely the envelope of the convective perturbation. For one particular ISV event, this envelope may be defined as the ensemble of regions that have a significant part of their intraseasonal signal with similar time-spectral characteristics. Such information may be extracted from the LMA of the OLR signal. The LMA makes it possible to detect and characterize in a simple mathematical form the most persistent modes of variability of a given time series for a given time frequency domain. The principle of the LMA analysis is to perform a series of complex empirical orthogonal function (CEOF) analyses on time sections succeeding one another in time and sufficiently short to avoid the mixture of different modes of variability (i.e., to have a large percentage of variance in the first principal component). This gives a more straightforward interpretation of the CEOF results. From the original time series of length $T$, a series of $M=(T-L) / \Delta L+1$ CEOF analyses are performed, where $L$ is the length of the time section considered for each analysis and $\Delta L$ is the lag between two CEOF analyses. For each time section of length $L$, the CEOF analysis gives for each region $x$, a time series of the form

$$
S_{x}(t)=A_{x} B(t) \cos \left[\phi_{x}+\chi(t)\right],
$$

where $t$ is time; $A_{x}$ and $\phi_{x}$ are, respectively, the regional amplitude and phase of the first complex eigenvector; and $B(t)$ and $\chi(t)$ represent the amplitude and the phase of the complex principal component. In addition, $A_{x}$ is normalized to be the standard deviation of $S_{x}(t)$. This signal represents for each region the part of the local intraseasonal perturbation of convection that is coherent at large scales. The final step is to select only the time sections corresponding to a local maximum in the time evolution of the variance percentage of the first CEOF. These time sections contain an event that has a spatial pattern that is more persistent than are those of nearby time sections. These persistent spatial patterns capture well the dominant events for an intermittent phenomenon (Goulet and Duvel 2000). First, this allows us to study such a phenomenon in more detail than is possible with a single average structure. Second, the LMA approach extracts objectively the precise pattern of variability for a given period and a given phenomenon and thus regions of interest for case studies of this phenomenon. This property is used to extract the spatiotemporal structure of the ISV of convection during winter 199899. The modulation of convective activity is deduced from the OLR time series filtered using a Kaiser-Bessel filter with a weight close to 1 in the 24-50-day band and an attenuation of 0.5 at 21 and 77 days. This filtering is necessary to avoid a mixing of time scales that may perturb the detection of the phase relation between regions. For the present analysis, the length $L$ of the time section is 120 days and the lag $\Delta L$ between two analyses is 10 days. For our period of interest, the two events with more persistent spatial patterns are centered, respectively, on 25 January 1999 and 11 March 1999. The variance percentage for January (56\%) is larger than for March (49\%). This means that the January event is the most persistent one for this 1998/99 winter season over the Indian Ocean. The spectral characteristics are also different with a characteristic time scale of around 35 
days for the January event and around 40 days for March.

\section{c. The ocean general circulation model (OGCM)}

The physical origin of the intraseasonal SST variability is investigated using the Laboratoire d'Océanographie Dynamique et de Climatologie (LODYC) OGCM (Madec et al. 1998). This is a primitive equation model discretized on a $\mathrm{C}$ grid with a free surface, an elaborate vertical mixing scheme (Blanke and Delecluse 1993), and a lateral mixing along isopycnic surfaces. We use a global version of the model with $2^{\circ}$ longitudinal resolution and a meridional resolution varying form $0.5^{\circ}$ at the equator to $2^{\circ}$ north and south of $20^{\circ}$.

This model is forced by daily mean momentum and heat fluxes given by the ECMWF 40-yr reanalyses (ERA-40; Uppala 2001; Simmons 2001). To prevent the model surface parameters from drifting away from the observed values, relaxations to the Reynolds and Smith (1994) weekly SST (with a $-100 \mathrm{~W} \mathrm{~m}^{-2} \mathrm{~K}^{-1}$ coefficient) and to the Levitus and Boyer (1994) sea surface salinity climatology were used with the same relaxation time. This relaxation might constrain the model variability at intraseasonal time scales too much and an alternative approach was developed to analyze the processes driving this intraseasonal SST variability. The model is first integrated with the relaxation above for $11 \mathrm{yr}$ between 1990 and 2000. The resulting relaxation terms are stored and low-pass filtered with a Hanning filter leaving $10 \%, 50 \%$, and $90 \%$ of the signal at, respectively, 75, 120, and 350 days. The model is then integrated for 1999 without relaxation but with these filtered relaxation terms applied as a flux correction to the ERA-40 heat and freshwater fluxes. This procedure constrains the model to stay close to the observed SST (and sea surface salinity) at seasonal and longer time scales, while leaving the intraseasonal variability unconstrained. As shown in section 5, heat flux correction terms for the region studied vary with periods larger than 2 months with maximum amplitude smaller than $40 \mathrm{~W} \mathrm{~m}^{-2}$. This has to be compared to the typical intraseasonal net heat flux variations that are up to 200 $\mathrm{W} \mathrm{m}^{-2}$ in 10 days.

Note that the relaxation to a climatological salinity product, which is necessary to limit the model drift, tends to dampen the interannual variability of the upperocean salinity field and thus can play some role in the upper-ocean heat budget (e.g., Lukas and Lindström 1991; Vialard and Delecluse 1998). However, this relaxation does not prevent intraseasonal surface salinity variability from appearing in response to atmospheric forcing. Note also that the absence of the diurnal cycle in the simulation may reduce significantly the intraseasonal variation of the SST (Shinoda and Hendon 1998).

The relative importance of the different physical processes contributing to the modification of the SST is diagnosed using the equation of evolution of the average mixed layer temperature $\bar{T}$ (a proxy for the SST). This equation can be written (Vialard et al. 2001)

$$
\begin{aligned}
\partial_{t} \bar{T}= & \frac{Q_{S}[1-f(H)]+Q^{*}}{\rho_{0} C_{P} H} \\
& +\frac{\left(K \partial_{z} T\right)_{-H}+\left(w_{-H}+d H / d t\right)\left(T_{-H}-\bar{T}\right)}{H}+A,
\end{aligned}
$$

where $H$ is the time-varying depth of the model mixed layer. Here, the mixed layer is defined as the ensemble of model layers with density lower than the surface density $+0.01 \mathrm{~kg} \mathrm{~m}^{-3}$. In the first right-hand-side term of Eq. (2), $Q_{S}$ is the net solar surface heat flux and $f(H)$, the fraction of the solar radiation that reaches depth $H$, given by

$$
f(H)=\operatorname{Re}^{-H / l_{1}}+(1-R) e^{-H / l_{2}} .
$$

In this study, we use $R=0.58, l_{1}=0.31 \mathrm{~m}$, and $l_{2}=$ $20 \mathrm{~m}$, which are characteristic of a type I water in the Jerlov (1968) classification and characteristic of the open-ocean clear water found in the region of interest. We use $Q^{*}$ for the nonsolar part of the heat flux (sensible + latent + long wave); $\rho_{0} C_{P}$ is the volumic heat capacity of seawater $\left(4 \times 10^{6} \mathrm{~J} \mathrm{~m}^{-3}\right)$. The second righthand-side term of Eq. (2) represents the overall effect of the heat exchanges between the deep ocean and the mixed layer. At the bottom of the mixed layer, $T_{-H}$ is the temperature, $w_{-H}$ is the vertical ocean motion, $\partial_{z} T$ is the vertical temperature gradient, and $K$ is the vertical mixing coefficient for tracers. Thus, $\left(K \partial_{z} T\right)_{-H}$ is the parameterization of the turbulent entrainment not resolved by the model, $w_{-H}\left(T_{-H}-\bar{T}\right)$ is the vertical heat advection, and $d H / d t$ is the entrainment speed at the spatial scale resolved by the model. As discussed in Vialard and Delecluse (1998), the terms $\left(K \partial_{z} T\right)_{-H}$ and $w_{-H}\left(T_{-H}-\bar{T}\right)$ are computed explicitly, following the model discretization, while, because of the particular form of the time discretization used in the model, the term $d H / d t\left(T_{-H}-\bar{T}\right)$ has to be computed as a residual. These three terms contribute to the cooling of the mixed layer in most situations, because the ocean is stably stratified and temperature generally decreases with depth. Only in the presence of strong salinity stratification can the temperature profile show an inversion and can this term become a heat source. The last term a of Eq. (2), $A$, is the overall contribution of lateral advection and diffusion.

\section{Synoptic description of the January and March 1999 intraseasonal events}

\section{a. Background circulation during JFM 1999}

Before describing in detail the January and March 1999 intraseasonal events, we will briefly describe the background atmospheric conditions during the January- 

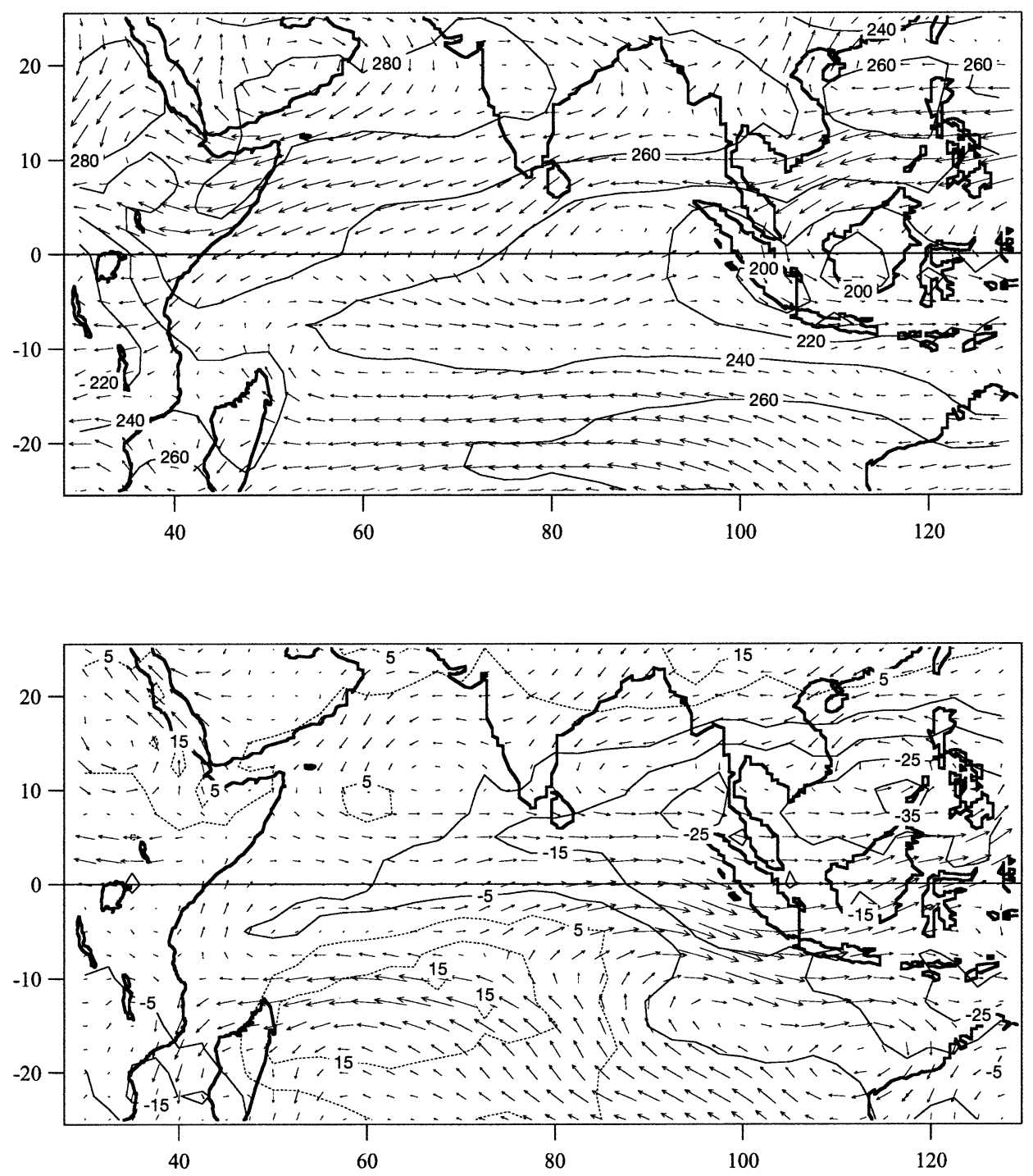

FIG. 1. (top) The 1974-2001 average of OLR $\left(\mathrm{W} \mathrm{m}^{-2}\right.$ ) and National Centers for Environmental Prediction (NCEP) 850-hPa winds for Jan-Mar. The length of the arrow is proportional to the wind speed with $1^{\circ}$ of latitude-longitude for a wind of $2 \mathrm{~m} \mathrm{~s}^{-1}$. (bottom) Difference between JFM 1999 and the 1974-2001 average for the OLR and the NCEP $850-\mathrm{hPa}$ wind. The length of the arrow is $1^{\circ}$ of latitude-longitude for a wind speed difference of $1 \mathrm{~m} \mathrm{~s}^{-1}$.

March (JFM) 1999 period compared to average conditions for the period 1974-2001. During the JFM season, the convective activity of the Indian Ocean area is mainly located south of the equator with a maximum above the Indonesian Islands (Fig. 1). In agreement with the simple steady-state model of Gill (1980), this is associated with an average low-level westerly inflow south of the equator. The southward location and the particular structure of the westerly wind maximum may be related qualitatively, through the Gill model, to the particular distribution of the convective activity (dynamical response to the elevated heating related to convection). The 1998/99 winter corresponds to a La Niña phase of the Southern Oscillation. This is associated with a large negative OLR anomaly over the whole Indonesian region in JFM 1999 extending up to $60^{\circ} \mathrm{E}$ around $10^{\circ} \mathrm{N}$ and up to $90^{\circ} \mathrm{E}$ around $10^{\circ} \mathrm{S}$ (Fig. 1). The large-scale OLR interannual anomaly is associated with a reinforcement of the westerly low-level wind, mostly south of the equator on the east side of the basin, and to a large low-level divergent and convectively suppressed region above the southwest Indian Ocean. There is a large low-level cyclonic anomaly southwest of Indonesia and a reinforcement of the cyclonic curl over the whole basin between the equator and $10^{\circ} \mathrm{S}$. Note that the zonally elongated cyclonic wind stress curl in the southern Indian Ocean (Fig. 1) results in Ekman pumping and thus a thermocline closer to the surface, as 

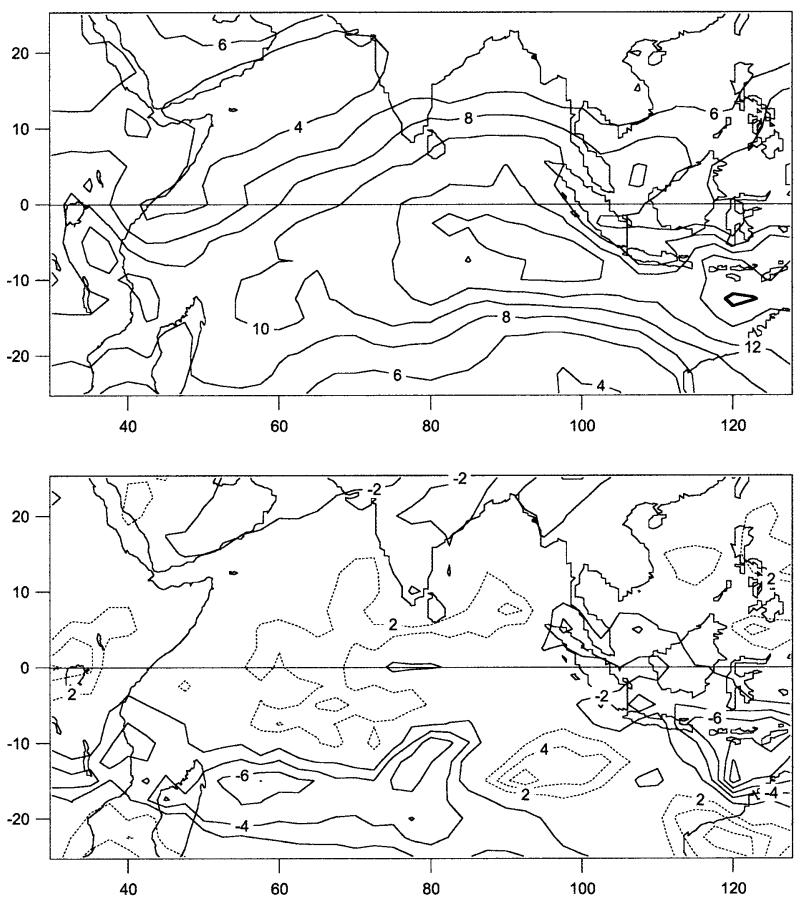

FIG. 2. (top) Average amplitude $\left(\mathrm{W} \mathrm{m}^{-2}\right)$ of the intraseasonal modulation of the OLR during JFM extracted from a local mode analysis between 1974 and 2001; (bottom) amplitude difference between the two modes of JFM 1999 and the 1974-2001 average.

suggested in Reverdin et al. (1986), and as can be seen in the Levitus and Boyer (1994) climatology.

The mean amplitude of the ISV of the OLR is obtained by averaging the amplitude of all the modes extracted by the LMA from JFM 1974 to JFM 2001. This amplitude is a maximum south of the equator with two maxima around $5^{\circ} \mathrm{S}, 90^{\circ} \mathrm{E}$ and $10^{\circ} \mathrm{S}, 120^{\circ} \mathrm{E}$ (Fig. 2). The JFM ISV of convection over the Indian Ocean may thus be seen as a periodic extension of the western and southern border of the ITCZ. Note that the ISV of convection is large above oceanic regions and small for the Indonesian Islands, over which the average convective activity is the strongest as was already discussed in Wang and $\mathrm{Li}$ (1994). The anomaly of the amplitude of the ISV of the OLR (Fig. 2) is computed as the mean anomaly for the two events of January and March 1999. Relative to the 1974-2001 average, the ISV of the OLR is smaller over the southwest Indian Ocean around $15^{\circ} \mathrm{S}$ because of the convectively suppressed condition. The ISV of the OLR is larger than the 1974-2001 average for most of the remaining regions of the Indian Ocean.

\section{b. The January ISV event}

For the January event the amplitude of the convective perturbation is relatively symmetric relative to the equator (Fig. 3). The convective perturbation propagates eastward with an average speed of $6 \mathrm{~m} \mathrm{~s}^{-1}$ at the equator between $60^{\circ}$ and $95^{\circ} \mathrm{E}$. The perturbation of convection is maximal on the west side of the ITCZ, represented here by the mean OLR signal for the 120-day window centered on 25 January. This event may thus be seen as a modulation of the longitudinal extension of the ITCZ. Note also the poleward propagation of the convective perturbation around $90^{\circ} \mathrm{E}$ that follows the eastward propagation.

The modulation of the SST field associated with the coherent large-scale modulation of the OLR is investigated using the results of the LMA analysis. For each region of $2.5^{\circ}$, the reconstructed signal [Eq. (1)] gives the date of the minimum OLR value. It is thus possible to construct a composite map of the SST perturbation on the basis of this information. We have divided the SST time series of each $2.5^{\circ}$ region into five periods of 5 days, one centered on the day of minimum OLR and four centered either 5 or 10 days before and after this minimum. The SST perturbation related to the intraseasonal perturbation of convection is expressed here as the difference between the averaged SST over the two periods giving the maximum and the minimum SST (Fig. 4). For the January event, the perturbation of the SST is maximal between $5^{\circ}$ and $10^{\circ} \mathrm{S}$ with values up to $3 \mathrm{~K}$. The difference between the SST perturbations north and south of the equator is rather surprising if one takes into account the quite symmetric distribution of the perturbation of the convective activity. This higher sensitivity of the SST south of the equator is studied in more detail in section 5 .

Six synoptic views, between 8 January and 2 February, of the SST, OLR, and ECMWF wind fields at 10 $\mathrm{m}$ are shown on in Fig. 5. The convective perturbation starts on the equator near $65^{\circ} \mathrm{E}$ around 8 January, in association with larger SST on the western side of the Indian Ocean. On 13 January, the convective perturbation extends in longitude and shifts southward in association with a transequatorial northerly flow west of $90^{\circ} \mathrm{E}$ that turns westerly south of the equator. Five days later there is an intensification of convection on the east side of the Indian Ocean (IO) basin associated with a strengthening of westerly winds around $7.5^{\circ} \mathrm{S}, 80^{\circ} \mathrm{E}$ and $10^{\circ} \mathrm{S}, 105^{\circ} \mathrm{E}$. At this stage, there is already a cooling of the southwest Indian Ocean (around $0.5 \mathrm{~K}$ ) and a warming to the east that tend to reverse the zonal SST gradient relative to the situation 10 days before. This may favor the extended convective perturbation on 23 January, associated with a large westerly wind event (all longitudes between $55^{\circ}$ and $110^{\circ} \mathrm{E}$ ), a cyclonic curl around $95^{\circ} \mathrm{E}$, and a strong cooling of the surface near $7.5^{\circ} \mathrm{S}, 80^{\circ} \mathrm{E}$. The convective perturbation envelope then shifts abruptly eastward, the surface water is further cooled, and the westerly wind perturbation and wind curl decrease. On 2 February, there is a rapid warming of the SST near $7.5^{\circ} \mathrm{S}, 80^{\circ} \mathrm{E}$ associated with suppressed convection and the westerly winds persist only west of $80^{\circ} \mathrm{E}$.

This ISV event is related to the generation of two cyclones (Birenda and Chikita) that started, respectively, on 26 and 30 January around $15^{\circ} \mathrm{S}, 95^{\circ} \mathrm{E}$. Birenda is visible in Fig. 5 (1-3 February around $\left.10^{\circ} \mathrm{S}, 70^{\circ} \mathrm{E}\right)$. This 

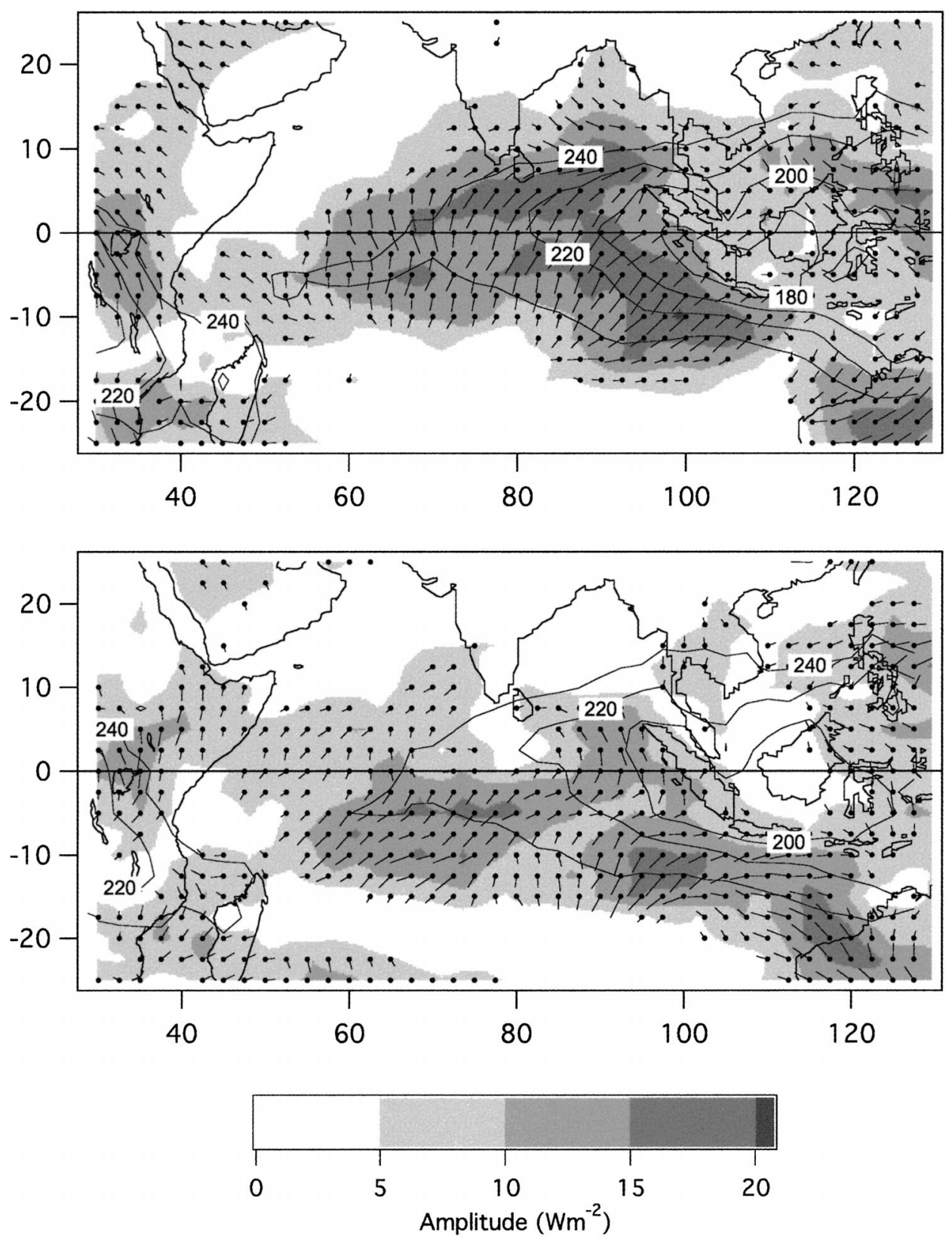

FIG. 3. Amplitude $\left(A_{x}\right)$ and phase $\left(\Phi_{x}\right)$ of the two events extracted from a local mode analysis for JFM 1999. The segment length is proportional to the amplitude $\left(A_{x}\right)$ and the angle of the segment represents the relative phase $\left(\Phi_{x}\right)$ of the periodic signal. A relative phase difference of $\pi$ represents a lag of the OLR signal of about 17 (20) days in Jan (Mar) between the considered regions. The angle increases clockwise with time (e.g., eastward propagation for a segment rotating clockwise toward the east). (top) Event centered on $25 \mathrm{Jan}$; (bottom) event centered on 11 Mar. The contour lines are for the OLR averaged over the time window of 120 days centered on 25 Jan and 11 Mar 1999, respectively.

is similar to the situation described by Ferreira et al. (1996) over the Indian Ocean in May 1986 with two cyclonic perturbations propagating poleward north and south of the equator as the ISV envelope reaches Indonesia but with only the southern one evolving to form a cyclone (Billy in 1986).

\section{c. The March ISV event}

For the March event, the amplitude of the convective perturbation is maximal south of $10^{\circ} \mathrm{S}$ (Fig. 3). This represents a modulation of the southern ITCZ border. There is no clear regular eastward propagation through 


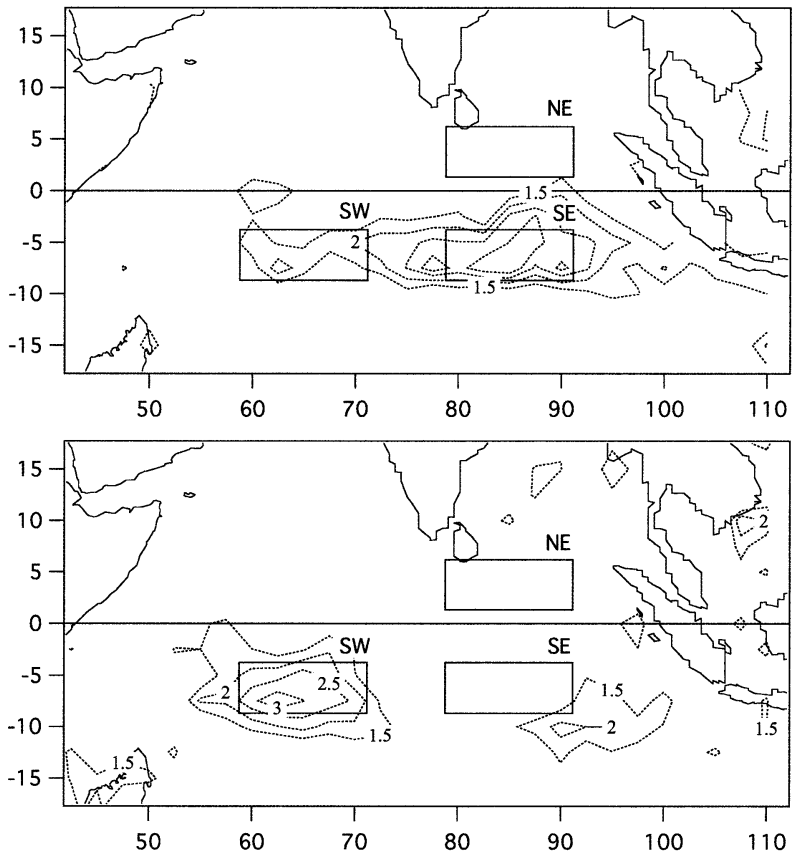

FIG. 4. Amplitude $(K)$ of the modulation of the SST around the date of maximum convection for the (top) Jan and (bottom) Mar events. This amplitude is estimated by taking the difference between the maximum and the minimum of a series of five pentad mean SST values centered within 10 days of the date of minimum OLR given by the LMA. The boxes define the three regions used in the detailed budget analysis.

the Indian Ocean, but rather a local eastward propagation east of $90^{\circ} \mathrm{E}$ with an average propagation speed of $4.5 \mathrm{~m} \mathrm{~s}^{-1}$ at $15^{\circ} \mathrm{S}$. The cooling of the SST associated with the convective development is also maximal south of the equator (Fig. 4). This SST perturbation is maximal $(3 \mathrm{~K})$ in the western part of the south Indian Ocean at the same location $\left(7.5^{\circ} \mathrm{S}, 62.5^{\circ} \mathrm{E}\right)$ as the secondary maximum for the January event.

Six synoptic views, between 3 and 28 March, of the SST, OLR, and ECMWF wind fields at $10 \mathrm{~m}$ are shown in Fig. 6. On 3 March, warm SSTs and convectively suppressed conditions prevail over the western Indian Ocean south of the equator. The Davina cyclone, visible near $12.5^{\circ} \mathrm{S}, 85^{\circ} \mathrm{E}$, is in its developing stage and is associated with a clear, cold SST anomaly. On 8 March, weak convective activity is developing over the warm water of the southwest Indian Ocean and the convection that previously prevailed north of the equator is decreasing. A westerly wind event then appears on 13 March south of the equator while deep convection grows east of $70^{\circ} \mathrm{E}$ and while the SST is cooling strongly west of the basin. Westerly winds still intensify around 18 March, in association with a northerly cross-equatorial flow west of $80^{\circ} \mathrm{E}$. The dynamics south of the equator are very similar to the situation around 23 January, where there is also a cyclonic perturbation of the lowlevel wind near $10^{\circ} \mathrm{S}, 90^{\circ} \mathrm{E}$. From 18 to $28 \mathrm{March}$, the convective activity shifts eastward, and the westerly wind decreases in intensity while the surface cools. There is a radical change of the SST structure during this organized March event with a shift of the warm water from the southwest to the northwest part of the Indian Ocean, corresponding to the seasonal migration of the warm water. The ISV perturbation of convection, and the associated dynamical perturbation, are thus important contributors to the timing and the characteristics of this seasonal evolution.

\section{Data and model evaluation}

Before using more quantitative arguments to physically interpret the SST variation on the basis of the atmospheric forcing given by ECMWF, SST data given by TMI, and ocean response given by the OGCM, we evaluate in this section some of the relevant measured or simulated parameters.

\section{a. Validation of the ocean model simulation}

The average thermocline depth (average upper-300m ocean temperature, T300, is used as a proxy) simulated by the model for this season agrees well with the Levitus climatology. The thermocline is closer to the surface between $5^{\circ}$ and $10^{\circ} \mathrm{S}$ (Fig. 7) with a minimum around $60^{\circ} \mathrm{E}$. This fact is clearly linked to the climatological wind structure in this region, where the cyclonic curl of the stress leads to strong Ekman pumping. The interannual variation of this thermocline depth is also remarkably well simulated, as may be seen by the comparison between 1999 anomaly maps of T300 and of the sea level anomaly observed by TOPEX/Poseidon. This interannual anomaly is strongest around $80^{\circ}-90^{\circ} \mathrm{E}$ with a thermocline even closer to the surface that can be related to reinforced Ekman pumping due to La Niña conditions. The region of high thermocline is associated with a very shallow mixed layer $(\sim 15 \mathrm{~m})$ between $5^{\circ}$ and $10^{\circ} \mathrm{S}$. The thermal stratification in this region, associated with relatively weak wind stresses, prevents the mixed layer from deepening. As is shown in section 5 , this shallow mixed layer south of the equator is the main factor explaining the largest SST sensitivity there compared to regions closer to the equator or in the Northern Hemisphere. The mixed layer south of the equator has similar spatial patterns but is shallower than for the climatology of Rao et al. (1989) who found values on the order of $30 \mathrm{~m}$. This is certainly due mostly to the different criterion used here to define the mixed layer depth (surface density $+0.01 \mathrm{~kg} \mathrm{~m}^{-3}$ ) compared to the Rao criterion (surface temperature $+0.5 \mathrm{~K}$ ).

The OGCM simulation also reproduces well the intraseasonal perturbation of the SST field, especially in the $5^{\circ}-12^{\circ} \mathrm{S}$ band (Fig. 8). This agreement in the general patterns makes us confident that the model captures the essential processes driving this intraseasonal SST variability. Note, however, that the model underestimates 

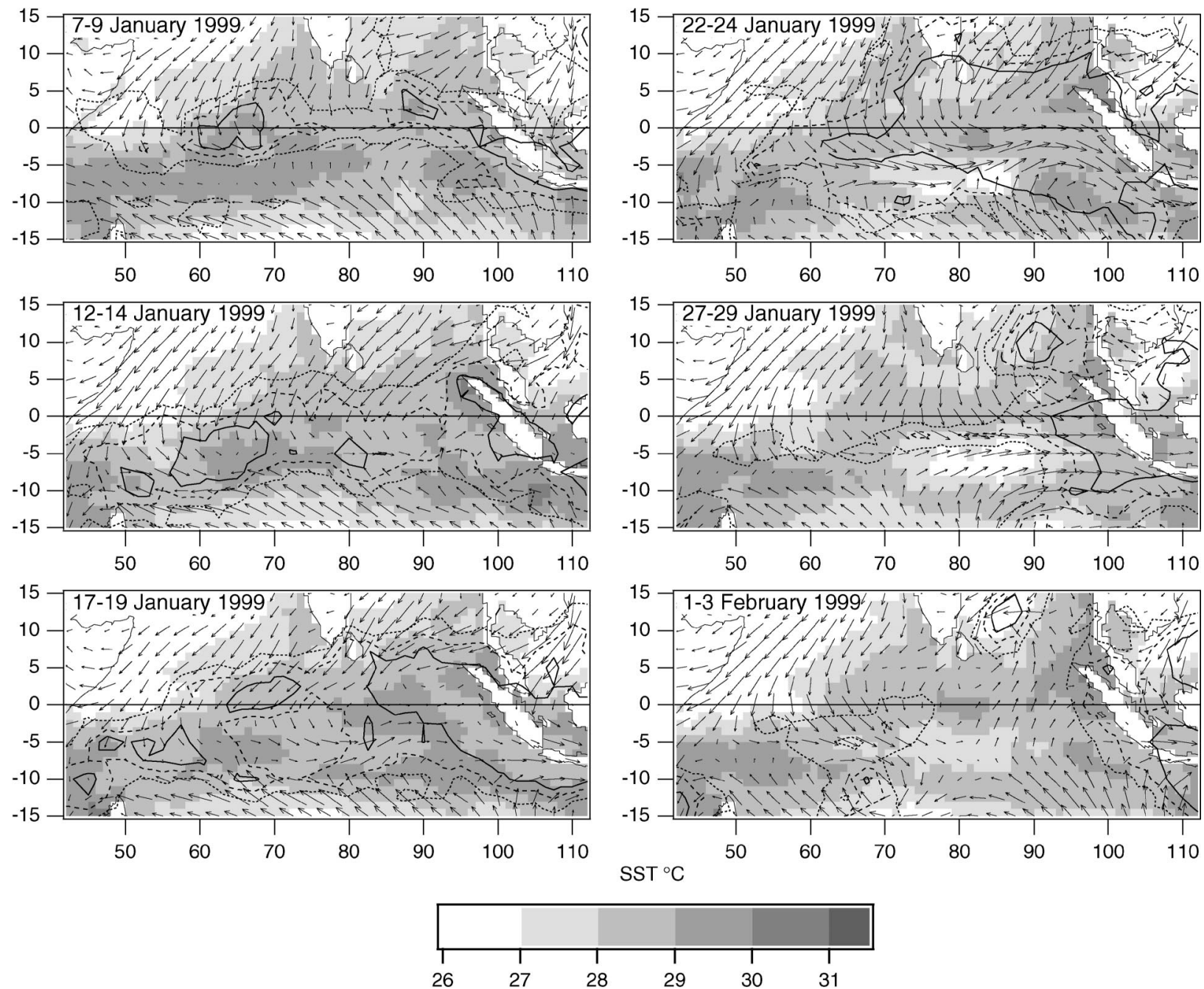

FIG. 5. Three-day-average maps of TMI SST (gray shading), OLR (contour), and ECMWF 10-m winds (vectors) around the central date of the Jan event. The length of the arrow is proportional to the wind speed with $1^{\circ}$ of latitude-longitude for a wind of $2 \mathrm{~m} \mathrm{~s}^{-1}$. The OLR contour lines are 180 (solid), 210 (dashed), and $240 \mathrm{~W} \mathrm{~m}^{-2}$ (dotted).

the amplitude of the intraseasonal signal. For example the heating (cooling) south of the equator reaches only $0.9^{\circ} \mathrm{C}\left(-0.9^{\circ} \mathrm{C}\right)$ for the $11(27)$ January against $1.2^{\circ} \mathrm{C}$ $\left(-1.2^{\circ} \mathrm{C}\right)$ over a larger region in the observations. As shown below, this is certainly due mostly to the fact that no warm layer is simulated in the model $(10-\mathrm{m}$ vertical resolution of the first layers and no diurnal cycle of the solar fluxes). The warm layer formation prior and/ or after the westerly wind burst contributes to the intraseasonal amplitude of the SST (Shinoda and Hendon 1998).

\section{b. Validation of ECMWF and TMI products}

Thanks to quasi-Lagrangian pressurized isopycnal balloons that were launched from the west coast of India during the INDOEX experiment (Ethé et al. 2002), the order of magnitude of the uncertainty in the ECMWF wind during January 1999, especially the westerly wind event, can be examined. We reproduce in Fig. 9 the trajectory and the deduced zonal and meridional wind of one balloon, with a long trajectory near $800 \mathrm{hPa}$ that crossed the equator. This is compared to the wind given by ECMWF analyses at the same location and pressure level (see Ethé et al. 2002 for the methodology and its validation). The overall spatiotemporal variation of the lower-troposphere wind during this January event is relatively well reproduced by ECMWF. The best fit is obtained over the trade wind region of the Arabian Sea. However, a striking result is the negative bias of $-5 \mathrm{~m}$ $\mathrm{s}^{-1}$ in the ECMWF zonal wind south of the equator (i.e., starting 23 January) with instantaneous values of the difference up to $-10 \mathrm{~m} \mathrm{~s}^{-1}$. Due to the relatively barotropic structure of these westerly winds perturbations, it is likely that this anomaly extends down to the surface. In such a case, this will overestimate the surface fluxes 

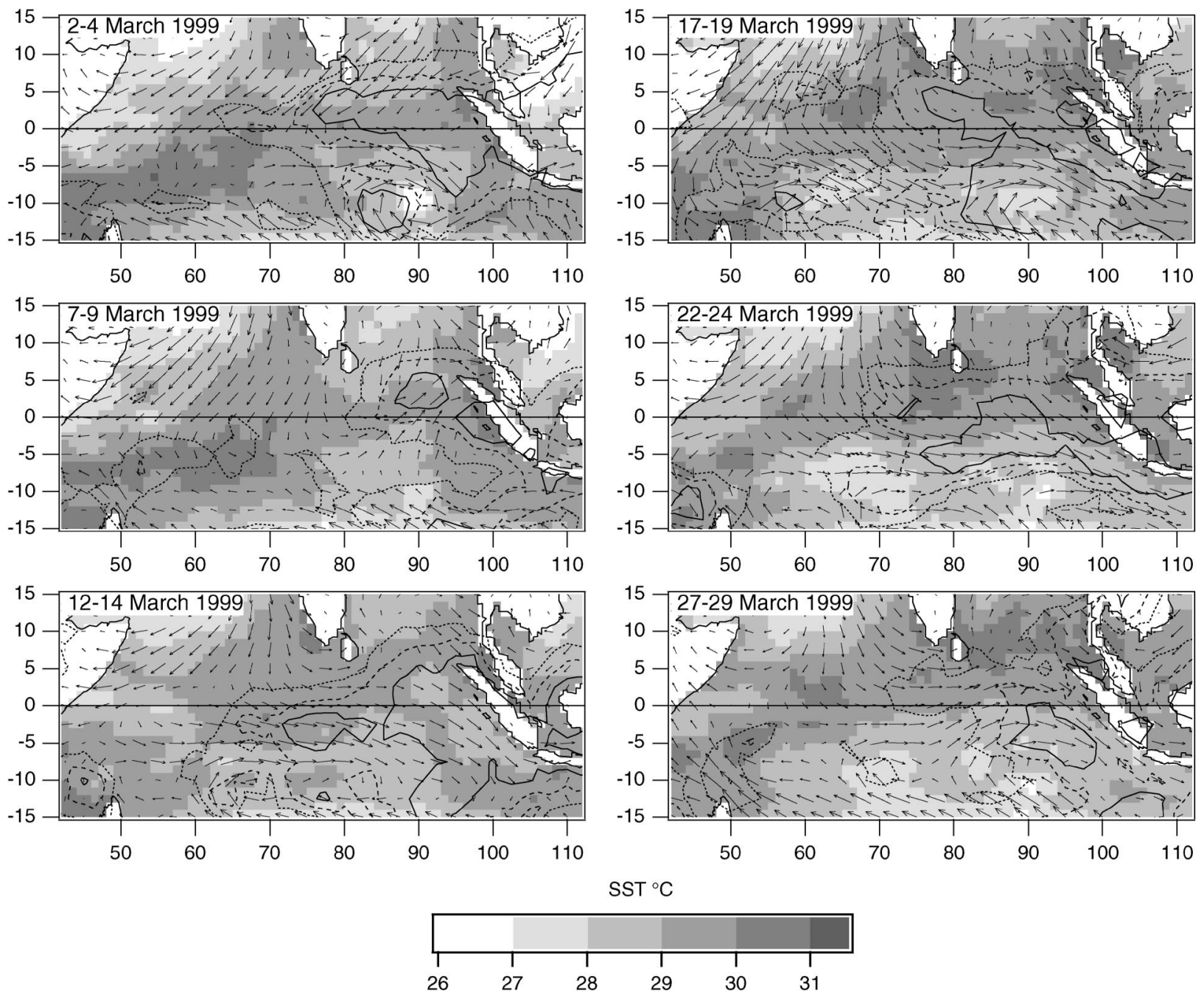

FIG. 6. As in Fig. 5 but for the Mar event.

for an easterly wind and underestimate them for a westerly wind. The meridional wind is better reproduced despite a tendency for a northerly anomaly south of the equator. This northeasterly bias may also lag the turbulent flux perturbation variations by a few days.

A necessary condition for interpreting the observed intraseasonal modulation of the SST using ECMWF analyses is that the convective ISV perturbation is also reasonably well described by the analysis system. For the three regions, there is indeed a good simulation of the OLR by ECMWF (see Fig. 11), especially for the regions south of the equator in January. It is interesting to note that these good simulations of the OLR are, however, obtained using a quite different evolution of the SST. Due to data availability of the weekly SST analyses, the SST used in the ECMWF analysis and forecast system is indeed lagged by about 5-10 days relative to the real SST. The SST difference between TMI and ECMWF is largest (nearly $2 \mathrm{~K}$ ) for the south- east region in January. This certainly has an impact on the temperature of the boundary layer, on convective instability, and on the large-scale dynamics. It is difficult to quantify the overall effect of this lag in the SST field without dedicated simulations. Concerning dynamical response, no particular lag in the wind field is apparent in Fig. 9. In fact, as was shown in Chiang et al. (2001), the heating of the midtroposphere is the main driver for the zonal wind in the tropical region. The assimilation of the temperature and humidity profiles from satellite measurements may thus result in a relatively correct modulation of the near-surface large-scale dynamics and may also explain the good simulation of the convective activity despite the lag in the SST field. In addition, assimilation of Meteosat-5 cloud motion winds at low and high levels improves the representation of the divergence field in this region (Köpken et al. 2001) and may contribute to the correct simulation of the convective activity. 

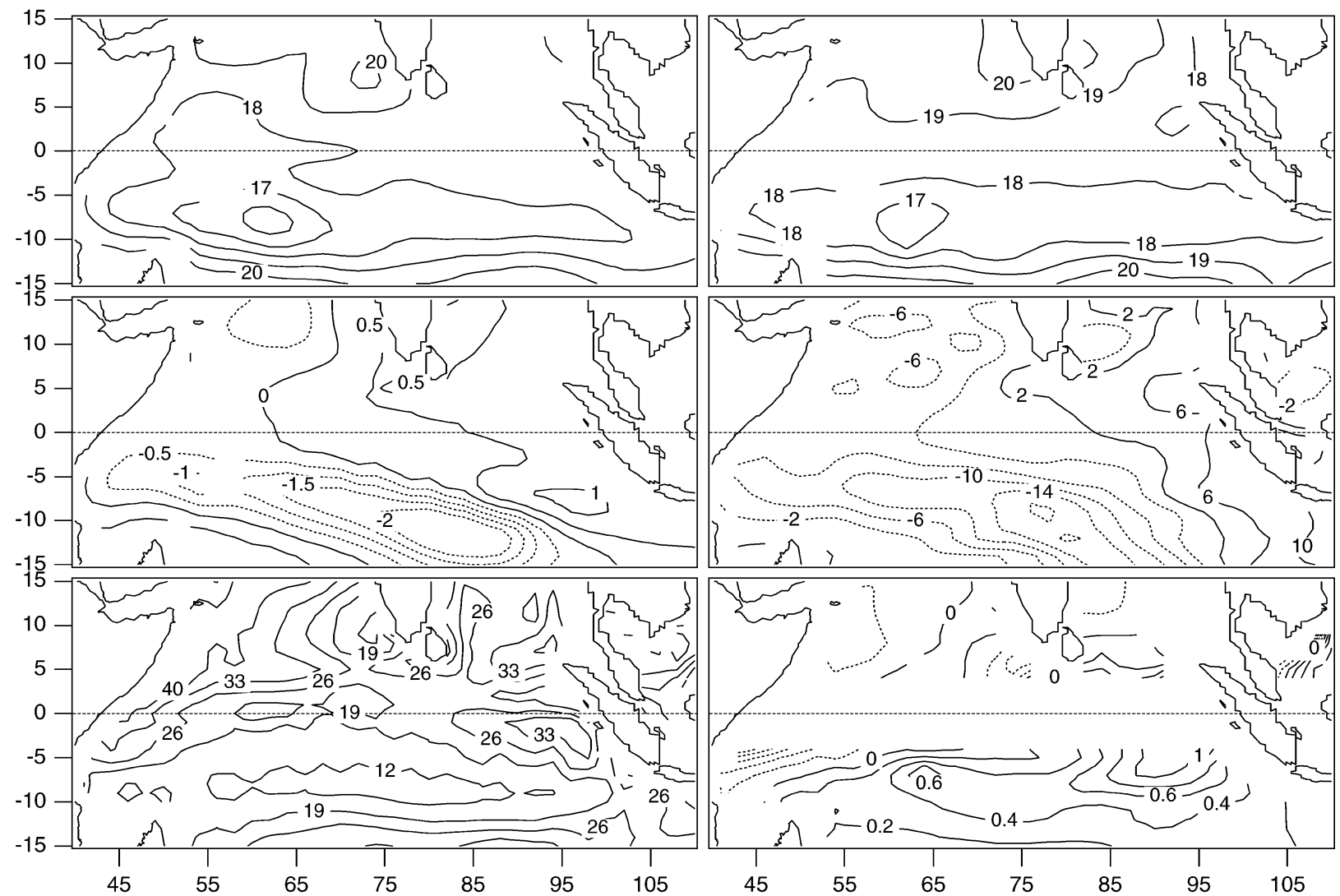

FIG. 7. Average upper-300-m ocean temperature (T300 in ${ }^{\circ} \mathrm{C}$ ) over the JFM 1990-2000 period in (top left) the OGCM simulation and (top right) for the Levitus climatology. (middle left) T300 anomaly simulated by the OGCM for JFM 1999 and (middle right) anomaly of the sea level anomaly (SLA in cm) from TOPEX in JFM 1999 compared to the 1993-2000 period. (bottom left) Average mixed layer depth simulated by the OGCM in JFM 1999. (bottom right) Ekman pumping computed from the OGCM forcing in $\mathrm{m}^{\text {day }}{ }^{-1}$.
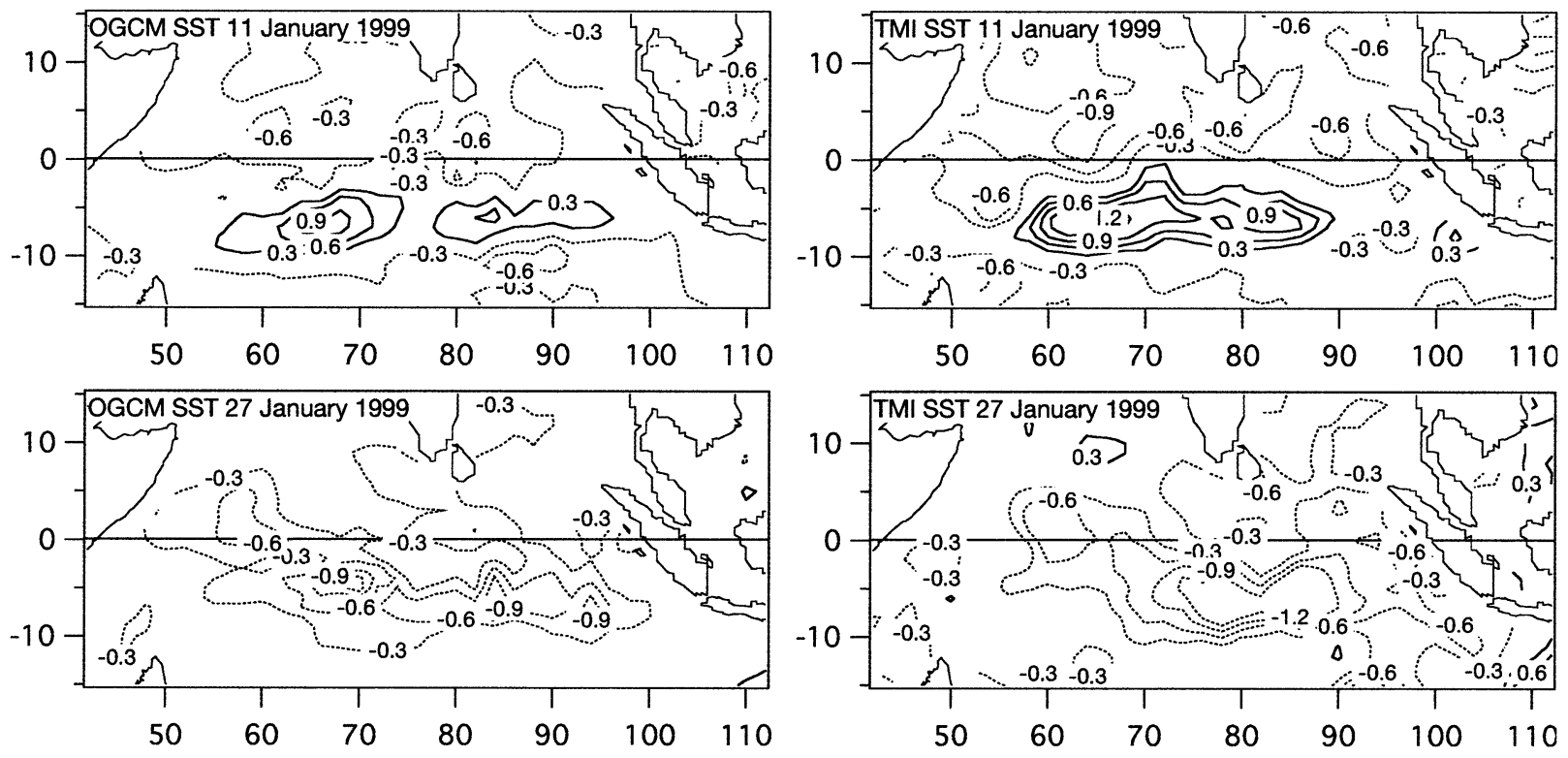

FIG. 8. Maps of the filtered SST perturbation (left) for the OGCM simulation and (right) for the TMI SST, for 11 and 27 Jan. 

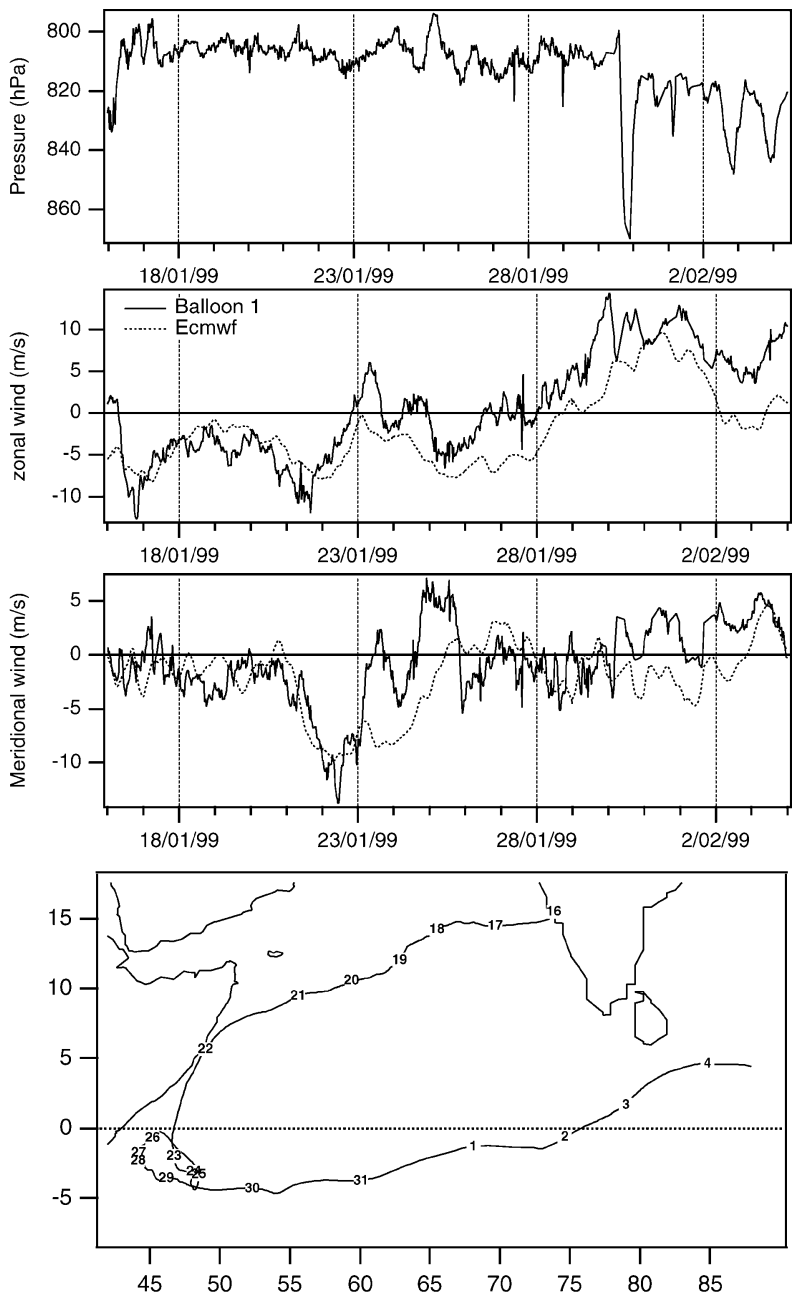

FIG. 9. Parameters of the first INDOEX balloon launched from the west Indian coast 16 Jan 1999. (top) Pressure level of the balloon. (middle top) Zonal wind deduced from the balloon trajectory and from ECMWF analysis at the same location and pressure level. (middle bottom) As above but for the meridional wind. (bottom) Trajectory of the balloon; the numbers are for the day of the month in Jan and Feb 1999 .

In ECMWF analyses, the reduction of the net surface flux $\left(Q_{S}+Q^{*}\right)$ by the convective perturbation is almost equally due to the surface latent heat flux $Q_{E}$ and to the net shortwave (solar) flux $Q_{S}$. Only the net surface flux is shown (see Fig. 11), with the alternative dataset obtained by replacing the ECMWF estimates of the latent and sensible turbulent fluxes $\left(Q_{H}+Q_{E}\right)$ by the estimates made from SSM/I measurements. The intraseasonal variability of these two estimates is in good agreement. However, the SSM/I dataset gives a smaller turbulent heat flux leading to net flux differences at the surface of, respectively, $+18,+32$, and $+25 \mathrm{~W} \mathrm{~m}^{-2}$ for the northeast, southeast, and southwest regions.

The SST perturbations in TMI data may be validated using World Meteorological Organization (WMO) buoys 23589 and 14549 that were in regions of large SST variations around $7^{\circ} \mathrm{S}, 75^{\circ} \mathrm{E}$ between 16 January and 30 March and around $8^{\circ} \mathrm{S}, 60^{\circ} \mathrm{E}$ between $25 \mathrm{Feb}-$ ruary and 30 March (Fig. 10). The TMI SST along the path of each buoy is estimated using a bilinear spatial interpolation and a linear temporal interpolation in the daily $1^{\circ} \times 1^{\circ}$ fields. For the east region, the TMI SST has a mean warm bias of $0.46 \mathrm{~K}$ relative to the temperature measured by the buoy. However, there is generally excellent agreement between the TMI and the buoy time series, particularly for the strong cooling depicted by TMI around 26 January. A warm-layer formation, with enhanced diurnal variation, is also apparent just prior to and after the westerly wind event of January (Fig. 5). For the west region, the TMI SST has a mean warm bias of $0.25 \mathrm{~K}$ relative to the temperature measured by the buoy. There is a strong diurnal variation of the SST depicted by the buoy between 25 February and 8 March that can be attributed to the formation of a warm layer during this period of low wind (Figs. 6 and 11). For this period the daily mean TMI SST has an overestimate of about $0.25 \mathrm{~K}$ with regard to the buoy diurnal average. The diurnal aliasing due to the orbital crossing time is quite complex to analyze since we are mixing diurnal and nocturnal orbits together with spatial and temporal interpolations in the final diurnal dataset. This aliasing appears, however, to be small in Fig. 10, even for the period of strong diurnal variation. The agreement between the buoy and TMI is very good after the strong cooling in March but more questionable during the cooling itself. This may be related to the more irregular spatial distribution of the SST during the cooling giving less consistency between the local buoy measurement and the interpolation in the $1^{\circ} \times 1^{\circ} \mathrm{SST}$ field.

\section{Physical origin of the SST perturbation}

\section{a. The northeast region}

For the northeast region, the strong perturbation of the convection in January is associated with a relatively weak perturbation of the surface wind. The perturbation of the net surface flux is thus mostly due to the radiative effect of the cloudiness. The perturbation of the SST is smaller than $1 \mathrm{~K}$ and corresponds mainly to a warm episode around 5 February due to a weakening of the surface wind and to a suppression of the convection (warm-layer formation). The evolution of the SST is characterized by a slow seasonal increase, well simulated by the OGCM (Figs. 11 and 12). This weak intraseasonal response of the ocean over the NE region is due to deeper thermocline and ocean mixed layer (Figs. 7 and 12). Here, the mixed layer depth fluctuation is large and closely related to the wind forcing (Figs. 11 and 12). The time series of the SST tendency terms in the OGCM mixed layer [Eq. (2)] reveals that the main source of seasonal and intraseasonal SST variability for this region is the surface fluxes (Fig. 12). Note that the 

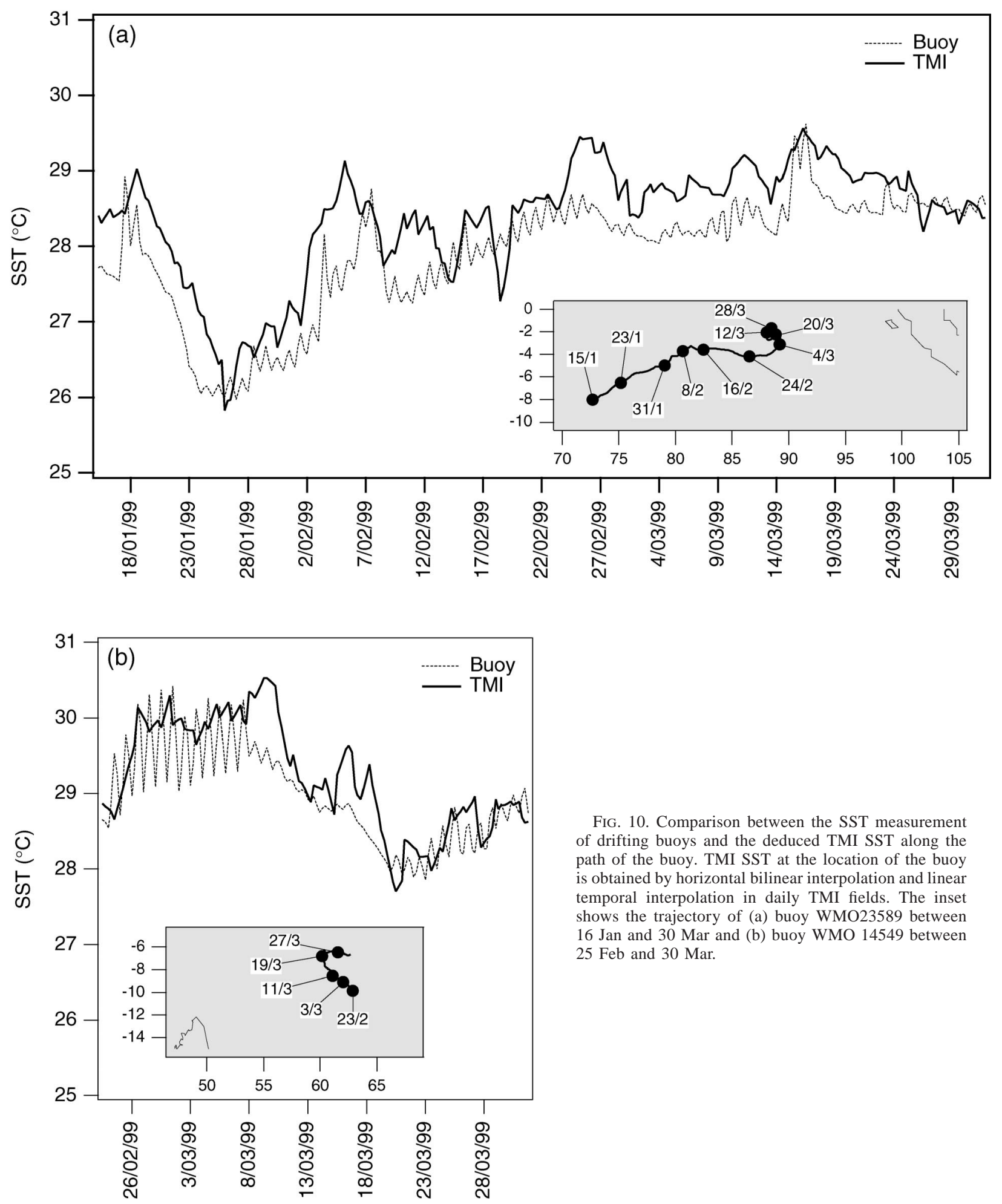

FIG. 10. Comparison between the SST measurement of drifting buoys and the deduced TMI SST along the path of the buoy. TMI SST at the location of the buoy is obtained by horizontal bilinear interpolation and linear temporal interpolation in daily TMI fields. The inset shows the trajectory of (a) buoy WMO23589 between 16 Jan and 30 Mar and (b) buoy WMO 14549 between $25 \mathrm{Feb}$ and 30 Mar.

flux correction term described in section $2 \mathrm{~d}$ is very smooth and weakly variable for this region and for the two regions south of the equator (Fig. 12) and thus does not perturb the intraseasonal SST variations.

\section{b. The southwest region}

For the southwest region and the January event, the phasing between the net surface radiative and turbulent 
FIG. 11. Time evolution of regional daily mean parameters for the three regions defined in Fig. 4. For each region, (top) TMI SST (thick line) and ECMWF analysis SST (thin line), (middle top) net surface fluxes from SSM/I (turbulent) and ECMWF analyses (radiative) (thick line) and from ECMWF (thin line), (middle bottom) NOAA OLR (thick line) and OLR from ECMWF analyses (thin line), and (bottom) ECMWF 10-m wind.

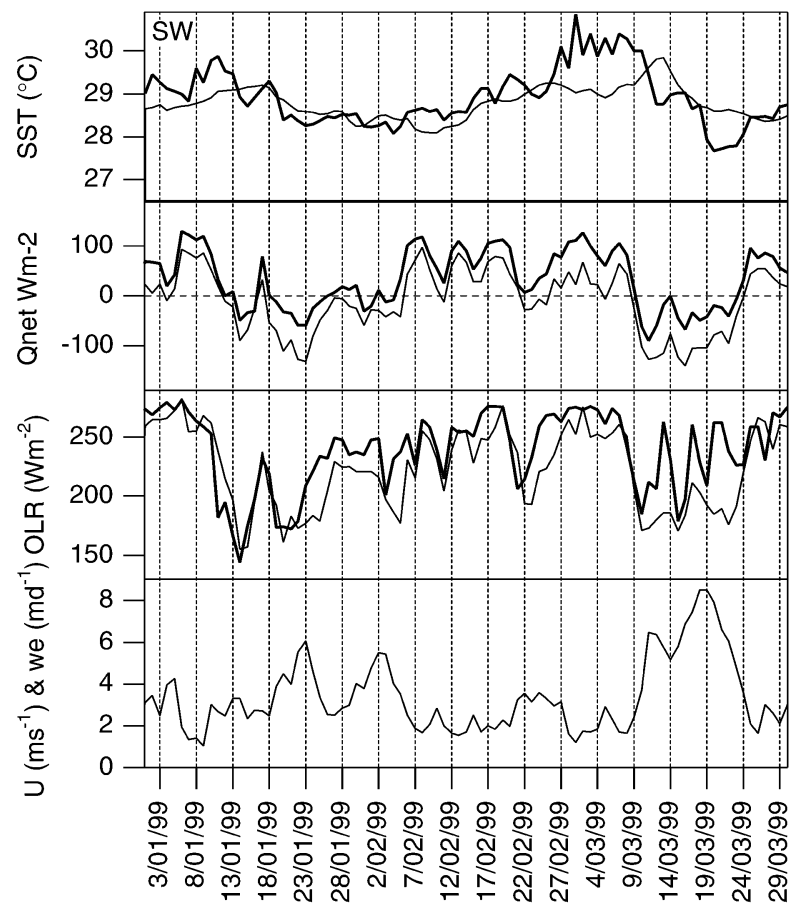

fluxes perturbations, due, respectively, to convection and surface wind, is relatively complex (Fig. 11). This is because the perturbation of the wind field south of the equator is related to the large-scale westerly wind event, starting around 18 January, which appears to be driven mainly by the strong convective perturbation to the east. The first convective event above the southwest region, maximal around 14 January, is thus not associated with a perturbation of the surface wind, while the

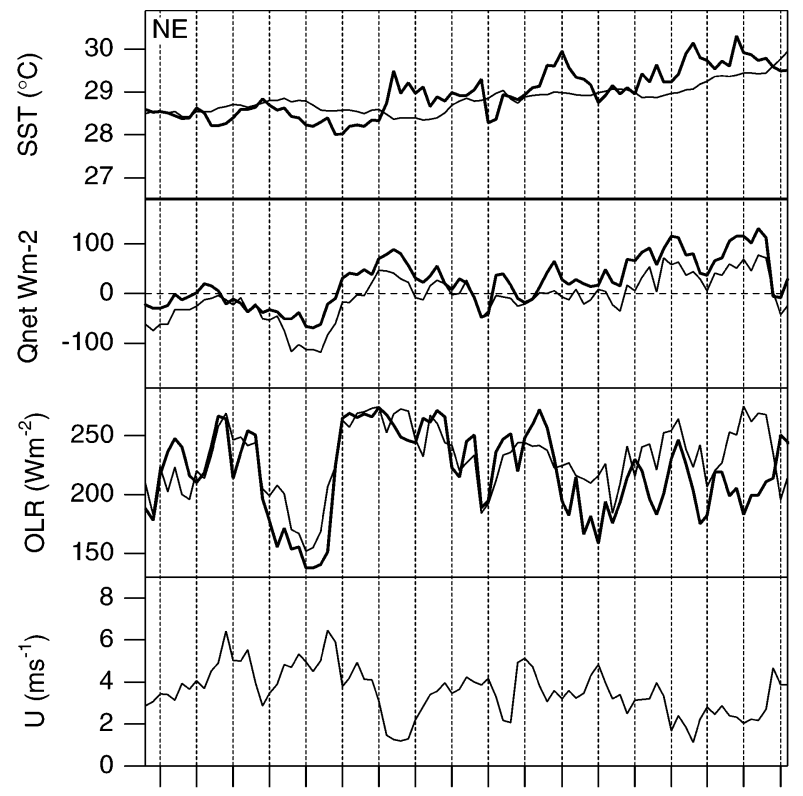

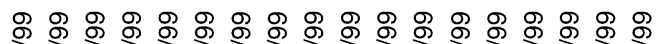

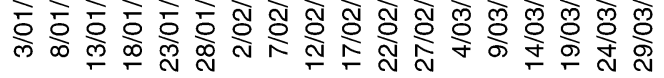

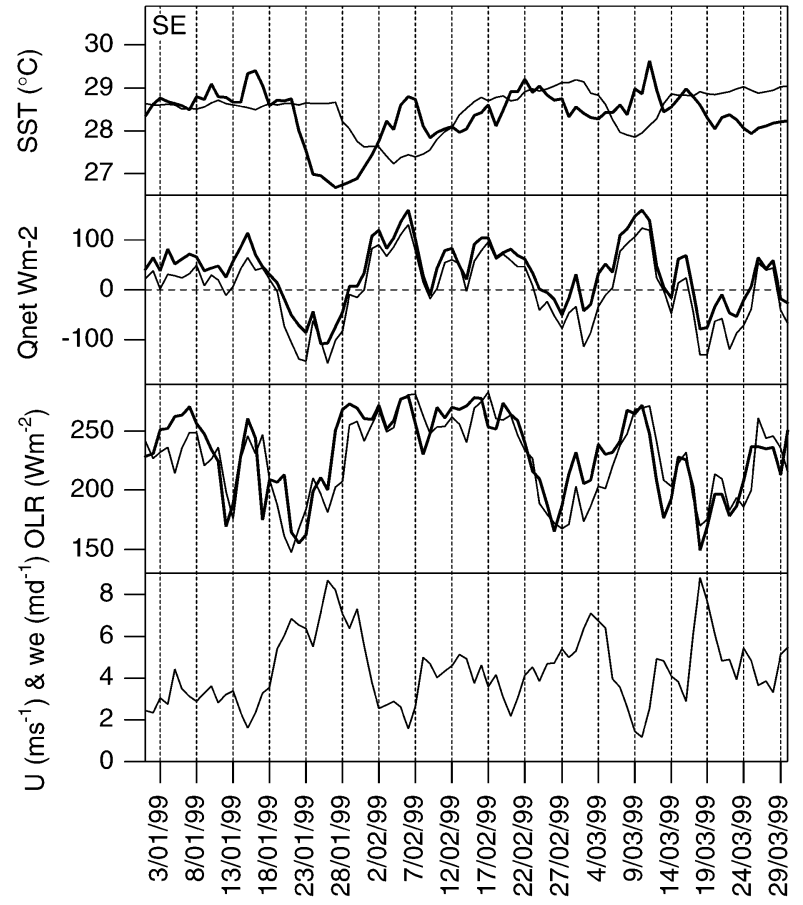

second convective event around 22 January is associated with the large-scale westerly wind event. This phasing between radiative and turbulent flux perturbations reduces and spreads out the perturbation of the surface fluxes. The resulting perturbation of the SST is a cooling of roughly $1.3 \mathrm{~K}$ in 12 days on average over the whole southwest region. Locally, the SST perturbation exceeds $2 \mathrm{~K}$ only near $7.5^{\circ} \mathrm{S}, 62.5^{\circ} \mathrm{E}$.

For the March event, the surface cooling is larger 
FIG. 12. Time evolution of regional daily mean OGCM mixed layer parameters for the three regions defined in Fig. 4. For each region, (top) TMI SST (thick line), OGCM SST (dotted line), and flux correction term (dashed line); (middle) SST tendencies due to the surface fluxes (thick line), to the entrainment at the bottom of the mixed layer (thin line), and to the horizontal advection and diffusion (dotted line); and (bottom) mixed layer depth.

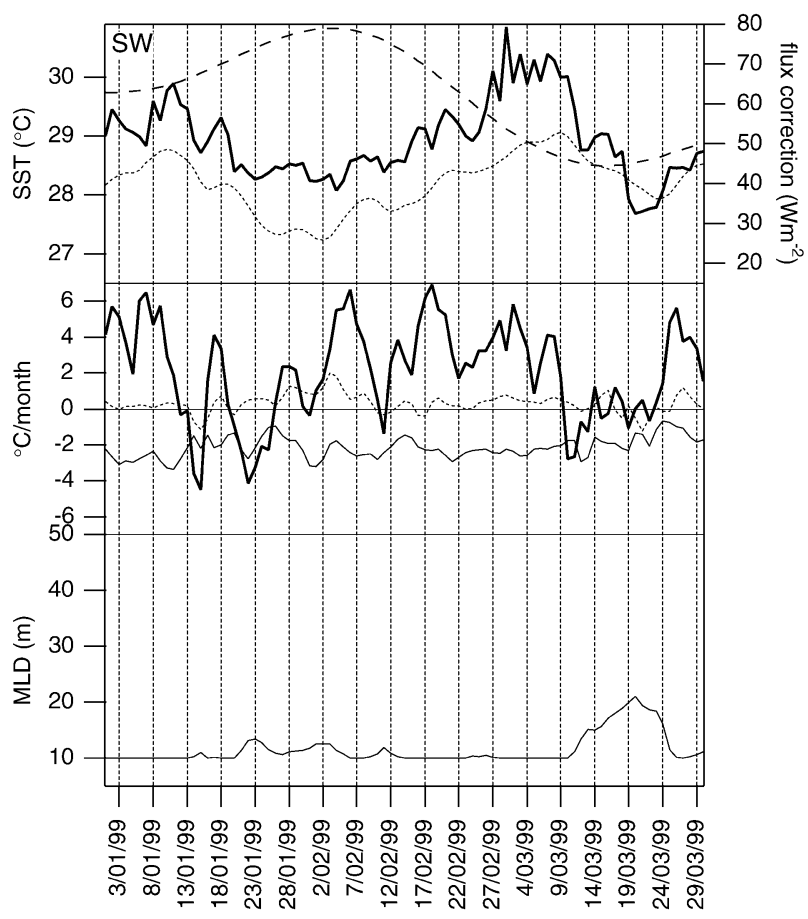

than for the January event $(2 \mathrm{~K}$ instead of $1.3 \mathrm{~K}$ in 12 days for the whole region). Locally, the perturbation of the SST in March exceeds 3 K (Fig. 4). The perturbation of the wind is larger in March and in phase with the convective perturbation. The larger amplitude of the SST perturbation in March is certainly related to the formation of a warm layer at the beginning of March (evident because of the stronger diurnal variation in Fig. 10), prior to the development of the convective pertur-

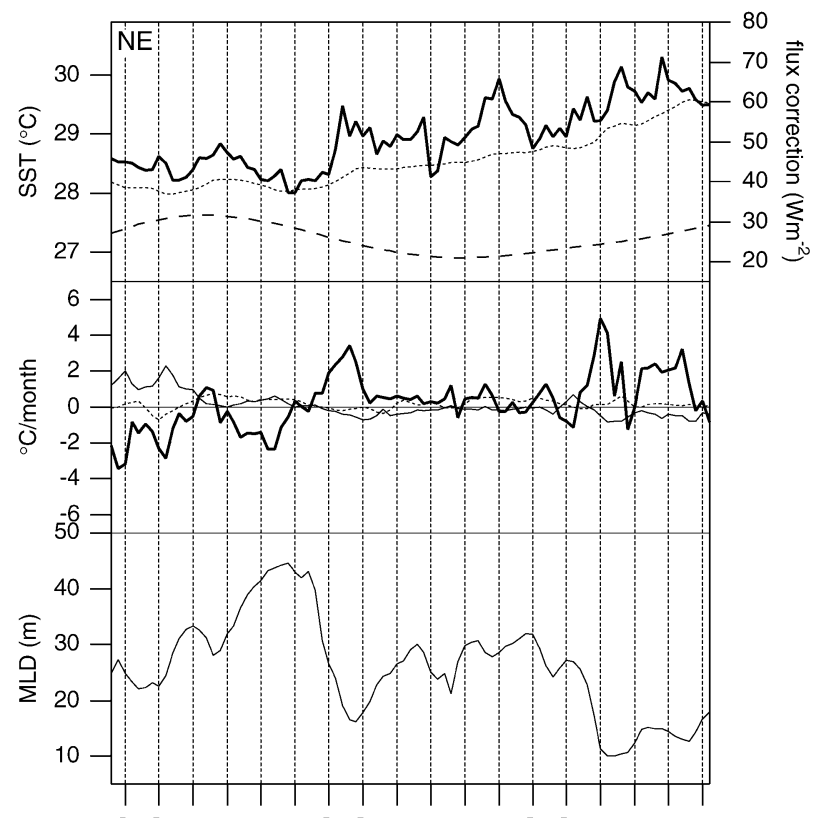

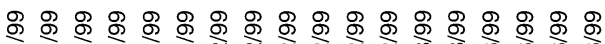
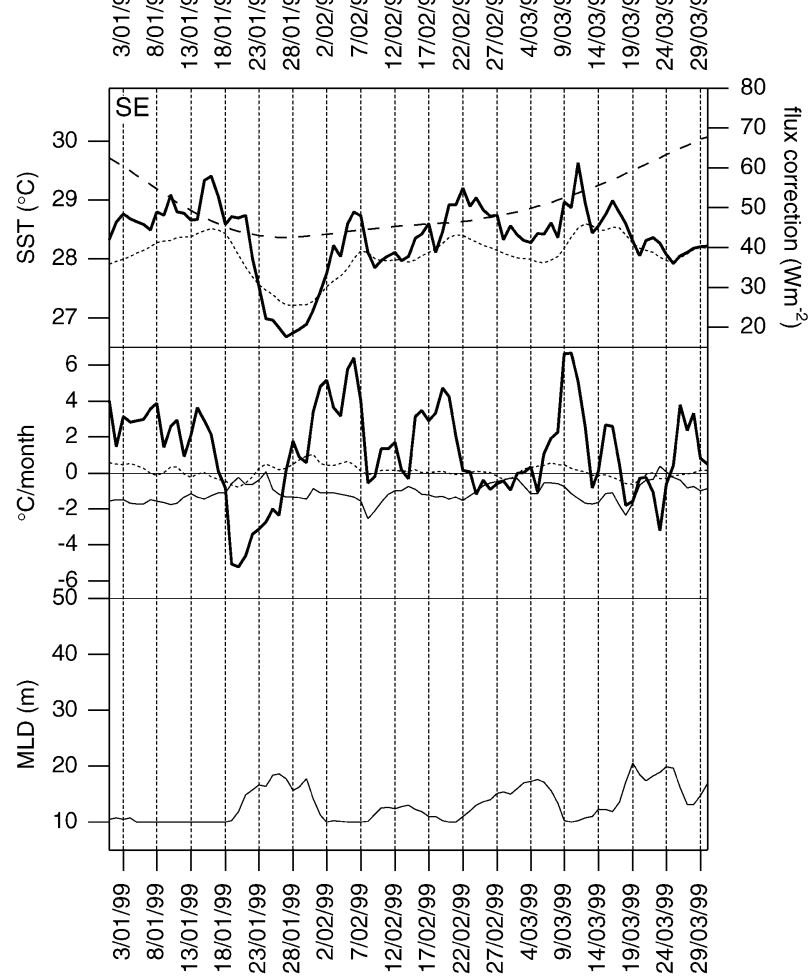

bation. This warm layer disappears rapidly as soon as the wind perturbation increases the vertical mixing. The OGCM simulates a permanent cooling of this region by entrainment at the bottom of the mixed layer. There are also some weak variations due to the exchange with the subsurface (which includes Ekman pumping and vertical mixing). The model simulates the SST evolution in January well but the strong SST perturbation in March is not well captured by the model, partly because 
of the absence of warm-layer simulation. Note, however, that TMI measurements overestimate the SST at the beginning of March along the buoy trajectory and may also overestimate it at the scale of the southwest region.

\section{c. The southeast region}

The southeast region experiences a strong cooling of the SST over a large region south of the equator during the January event (Fig. 11). This cooling event is relatively well captured by the OGCM simulation (Fig. 12) and is studied in more detail in this section. The flux perturbation is strong and well localized in time, despite the lag of about 5 days between the minimum OLR and the maximum wind perturbation (the maximum westerly wind is located west of the convective perturbation). The region loses energy at the interface between 18 and 29 January with peak values around $-150(-110) \mathrm{W}$ $\mathrm{m}^{-2}$ for the ECMWF (SSM/I) estimates. The warming phase of the surface in the observation is difficult to understand, because part of this warming occurs between 25 and 29 January while the net flux at the surface is still negative (for both estimate of the turbulent fluxes by ECMWF and SSM/I). Note that this warming occurs in three different phases: between 25 and 29 January, when the wind is still strong and the net flux negative; between 29 January and 2 February, when the wind decreases and the net flux is positive; and an additional warming after 2 February (more evident in Fig. 10) with positive net flux and weak winds. The sharp increase after 2 February appears to be more probably related again to the formation of a warm layer for this phase of weak wind. The first phase is the more troublesome and could be attributed to a lag in the ECMWF fluxes. The SST simulated by the OGCM does not show such an SST increase during the period of negative flux.

As for the two previous regions, the GCM indicates that lateral advection and diffusion do not contribute significantly to the heat budget of these regions. The weak variations due to the exchange with the subsurface (which includes Ekman pumping and vertical mixing), also present for the southwest region, seem to be a consequence rather than a cause of the intraseasonal variability of the SST. In fact, the mixed layer cools quicker than the subsurface during the westerly wind burst (not shown). That can easily happen with such a thin mixed layer for which a significant fraction of the incoming solar heat flux is lost through the layer bottom (20\% for a 15-m layer for the water properties used in this study). The heat loss during the westerly wind burst is then concentrated in the surface layer, while the subsurface is still slightly warmed by solar heat flux. Examining latitude-time sections of wind stress, net heat flux (including the heat flux correction), SST, and mixed layer depth reveals a clear latitudinal shift between the atmospheric forcing and the oceanic response (Fig. 13). The net heat flux perturbation is maximal near the equator and the wind stress perturbation is maximal at $5^{\circ} \mathrm{S}$.

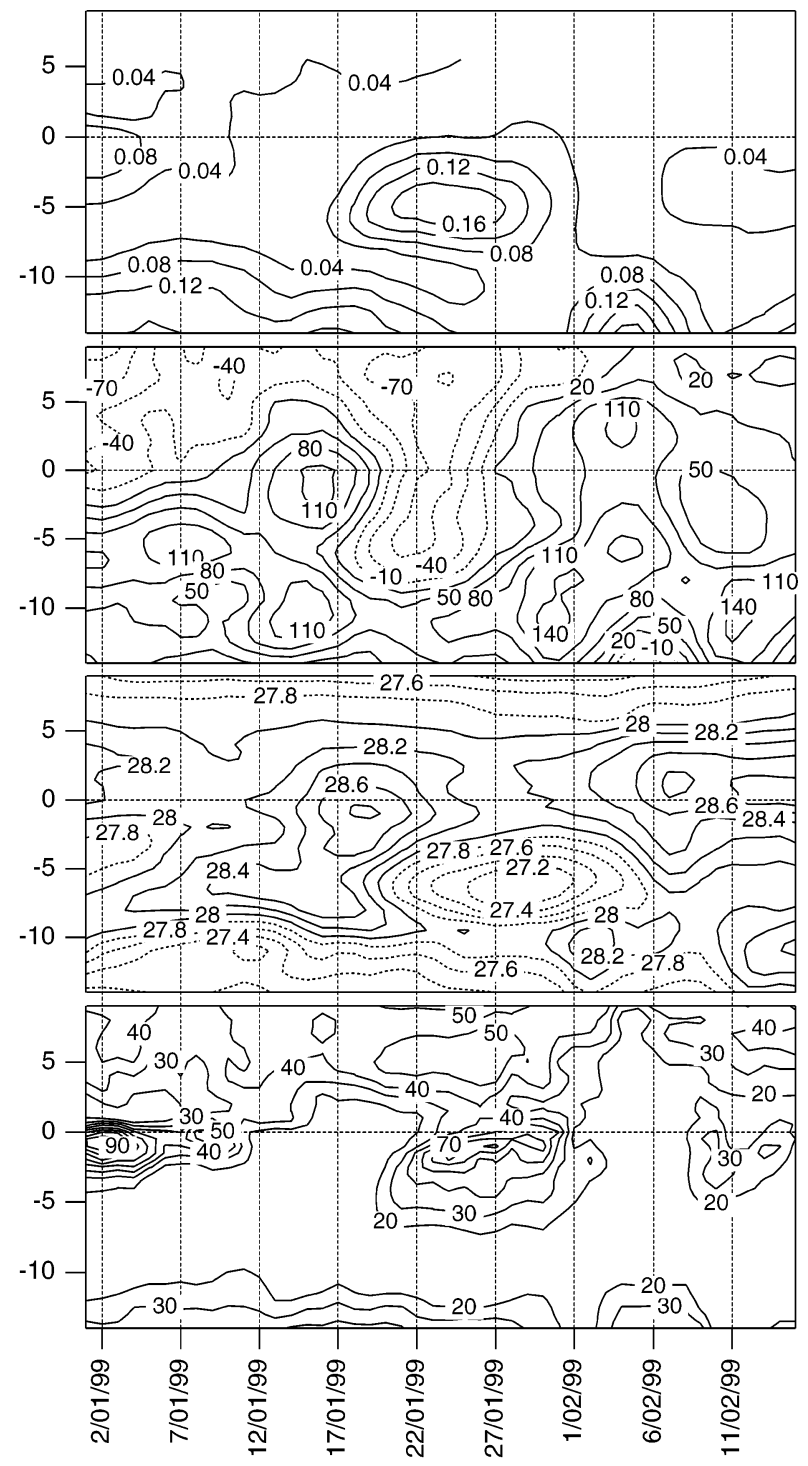

FIG. 13. Time-latitude diagrams of the evolution of (top) wind stress in $\mathrm{Pa}$, (middle top) net surface flux in $\mathrm{W} \mathrm{m}^{-2}$, (middle bottom) temperature of the mixed layer in ${ }^{\circ} \mathrm{C}$, and (bottom) mixed layer depth in $\mathrm{m}$ for the OGCM. Values are averaged between $80^{\circ}$ and $90^{\circ} \mathrm{E}$.

The mixed layer deepening is, however, maximal at the equator and hardly extends south of $5^{\circ} \mathrm{S}$. The resulting perturbation of the mixed layer temperature is maximal near $7^{\circ} \mathrm{S}$, that is, south of the maximum wind stress perturbation. Near and north of the equator, the relatively deep mixed layer tends to lessen considerably the impact of the surface flux anomaly. South of the equator, the mixed layer stays relatively shallow, even during the westerly wind burst and is thus more reactive to the surface flux perturbation. The latitudinal shift between the wind forcing and the mixed layer depth response south of the equator is mostly due to the latitudinal variation of the ocean stratification (shallower thermocline at $10^{\circ} \mathrm{S}$ for this region and deepening equatorward; Fig. 7). 
To explore this in more detail, the vertical distribution of temperature, salinity, and current perturbation are also analyzed for the regions around the equator and around $5^{\circ} \mathrm{S}$. The difference in the mixed layer responses for these two regions is indeed reinforced by other processes. First, Ekman dynamics associated with the westerly wind burst tend to create a weak downwelling in the equatorial region, and an upwelling in the southern region (Fig. 14). This upwelling contributes toward maintaining the salinity and temperature stratification very close to the surface and, thus, to inhibiting the mixed layer deepening. The large precipitation signal here also contributes to the stabilization of the upper ocean by decreasing the surface salinity. In the equatorial region, the upper-ocean current response and the associated vertical shear are larger than for the southern region despite the smaller wind stress perturbation. This large shear, together with the downwelling and weak background stratification, lead to a larger deepening of the mixed layer close to the equator.

\section{Summary and discussion}

The response of the ocean mixed layer to intraseasonal forcing by convective activity and large-scale dynamics was studied for two events over the Indian Ocean region in January-March 1999. The main findings of this analysis include the following.

- For both events, the modulation of convective activity, surface zonal wind, surface fluxes, and SST are maximal south of the equator. There is no significant modification of the SST north of the equator in January despite large convective and surface flux perturbations.

- The perturbation of the temperature of the mixed layer is the strongest around $7.5^{\circ} \mathrm{S}$. As shown by the OGCM simulation, this is due to a strong stratification close to the surface south of the equator that limits the mixed layer deepening and thus concentrates the effects of the flux perturbation near the surface. Other factors like the Ekman dynamics associated with the wind burst and the precipitation perturbation south of the equator also contribute to keep the mixed layer thin. The entrainment at the bottom of the ocean mixed layer appears to play a little role.

- The perturbation of the surface fluxes is nearly equally due to the reduction of the insolation by the convective cloudiness and the increase of the evaporation linked to the large-scale dynamical perturbation (westerly wind events). Since the modulation of the SST is mainly related to these fluxes, the phasing between the convective and the dynamical perturbation is a determining factor for the amplitude of the SST perturbation.

There are also some technical conclusions regarding the validation of the ECMWF analyses and of the SSTTMI dataset.
- The regional OLR simulated from the ECMWF analysis procedure is in remarkable agreement with observations for the period and the region considered.

- Comparison with quasi-Lagrangian balloon trajectories shows that the intraseasonal variations of the wind field in the lower troposphere is well reproduced. However, there is a negative bias of the zonal wind, mainly south of the equator during the January westerly wind event. This bias, if also present at the surface, may be a source of error in the modulation of the surface turbulent fluxes by large-scale dynamics, especially by underestimating the effect of the westerly wind events.

- Comparison with in situ SST measurements made by drifting buoys shows a remarkable agreement with the TMI-SST dataset and confirms the formation of a warm layer in the western part of the Indian Ocean south of the equator prior to the March event.

This study shows the complexity of the processes at the origin of a strong SST perturbation associated with winter intraseasonal convective perturbations over the Indian Ocean. Such a study must be extended in order to verify the validity of these processes for other years. Preliminary results (not shown) confirm that for the 1998-2002 period the intraseasonal variation of the SST over the Indian Ocean during January-February is indeed maximal around $7.5^{\circ} \mathrm{S}$ and weak at and north of the equator.

For both intraseasonal events in 1999, there was a profound modification of the large-scale SST fields with a general cooling of the regions between the equator and $10^{\circ} \mathrm{S}$. Such a strong modification of the structure of the SST field could be an important parameter for the timing between two intraseasonal events and for the evolution of convective intraseasonal perturbations. A change in the horizontal structure of the SST field at intraseasonal time scales could indeed modify the distribution of the convective instability and thus the warming of the middle troposphere. According to Chiang et al. (2001), this warming of the middle troposphere is more efficient than the SST-induced boundary layer warming to force large-scale surface winds such as the westerly wind events. An important issue will be to understand the precise nature and impact of this interaction by performing dedicated model simulations. If this mechanism plays a significant role, the interannual variability of the mean stratification of the ocean for a given year may be critical for the development and the evolution of the ISV. Indeed, interannual changes of the upper-ocean structure in the OGCM affect the mixed layer depth during winter in this region. To illustrate this point, the physical origin of the interannual variation of the January-March mixed layer depth is investigated by computing the interannual (1990-2000) correlation between the mixed layer depth and the three factors that control it: the wind stress, the buoyancy flux, and the stratification (T300). Over a relatively large 


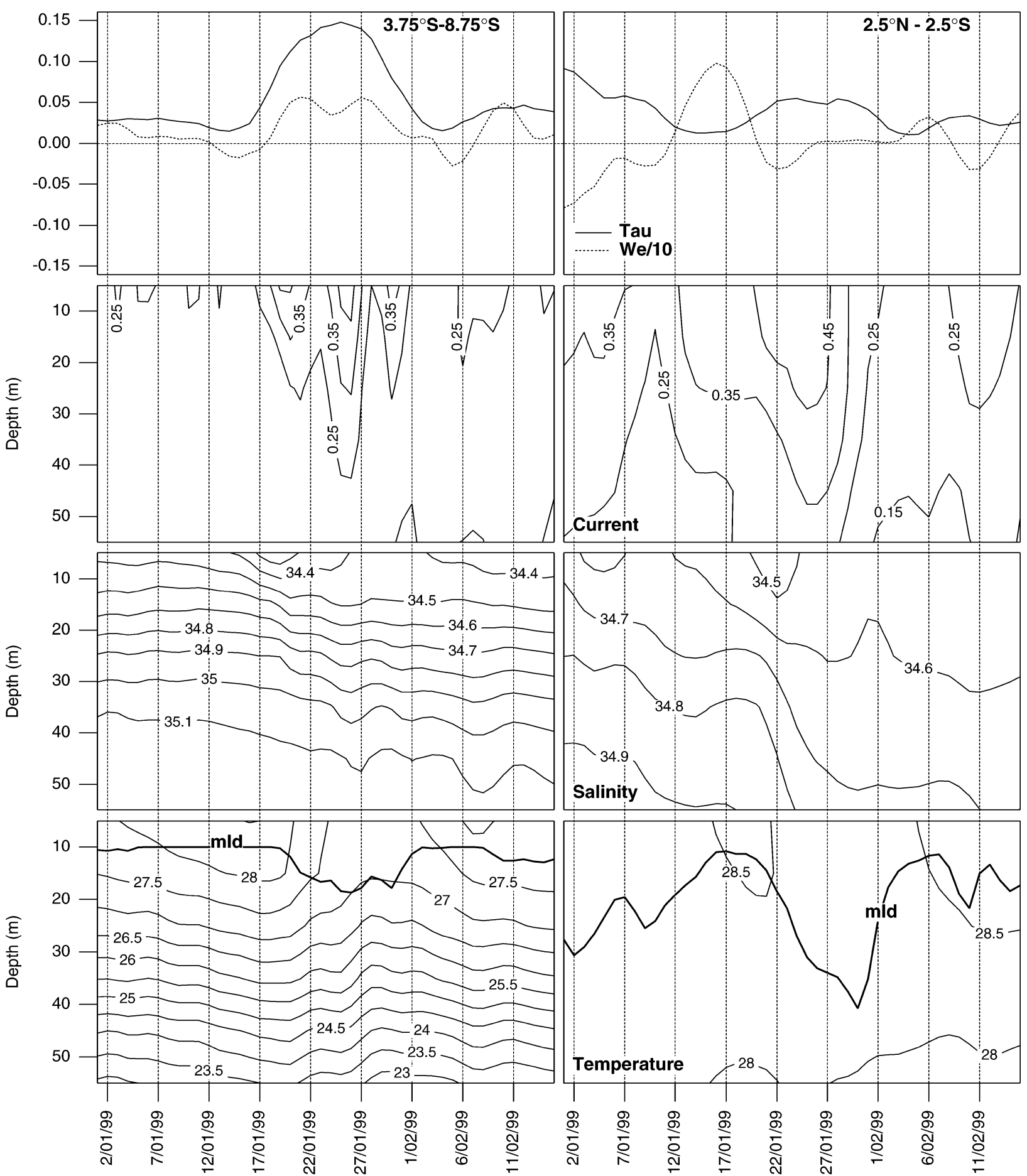

FIG. 14. Evolution of average OGCM forcing and response terms between $80^{\circ}$ and $90^{\circ} \mathrm{E}$ for two latitude bands (right) between $2.5^{\circ} \mathrm{N}$ and $2.5^{\circ} \mathrm{S}$ and (left) between $3.75^{\circ}$ and $8.75^{\circ} \mathrm{S}$ : (top) wind stress in Pa and ocean model $0-100-\mathrm{m}$ integrated vertical velocity in $\mathrm{m}$ day ${ }^{-1}$, (middle top) time-depth cross section of the horizontal current in $\mathrm{m} \mathrm{s}^{-1}$, (middle bottom) time-depth cross section of the salinity in psu, and (bottom) time-depth cross section of the temperature in ${ }^{\circ} \mathrm{C}$ and depth of the mixed layer in $\mathrm{m}$.

portion of the region of strong SST intraseasonal variability $\left(5^{\circ}-10^{\circ} \mathrm{S}\right)$, the mixed layer depth is significantly correlated to T300 only (Fig. 15). The control by the wind stress is more evident in trade wind regions and over the eastern equatorial Indian Ocean while the control by the buoyancy plays a role south of our region of interest. This suggests that the interannual variability of the thermocline depth in this region has a systematic 

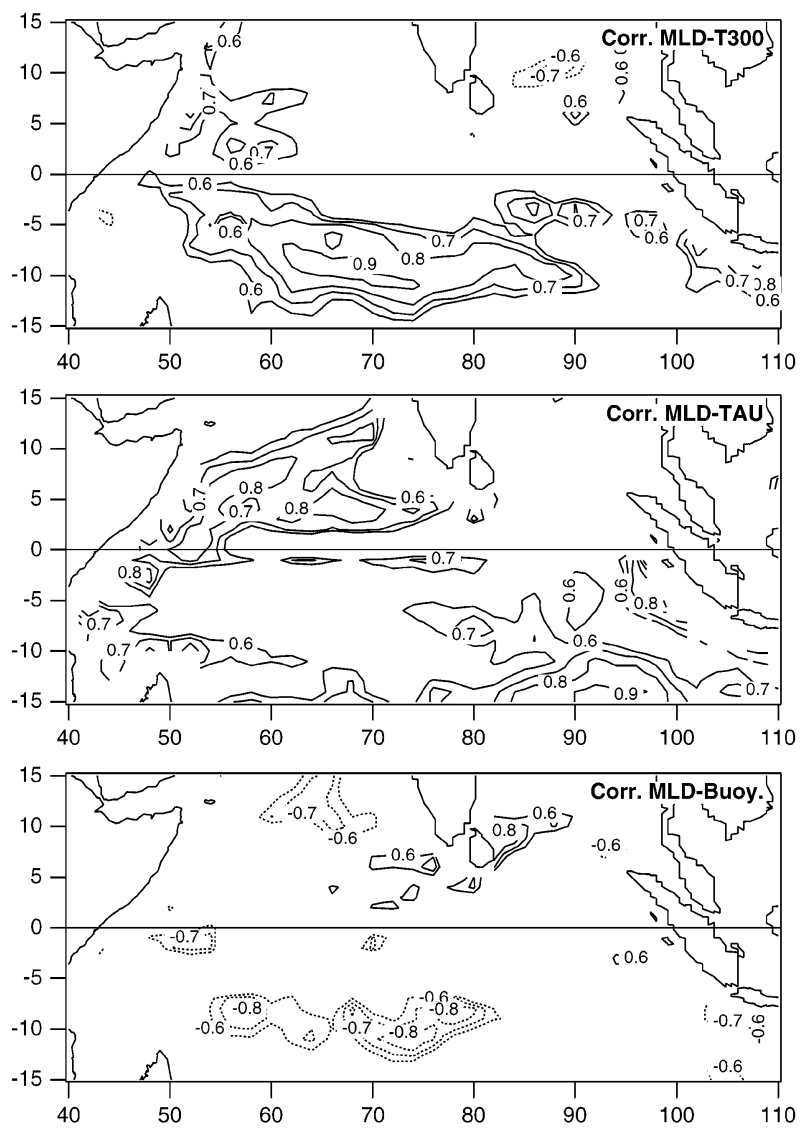

FIG. 15. Correlation between the JFM average mixed layer depth of each year from the OGCM simulation (1990-2000) with (top) the average upper-300-m ocean temperature, (middle) the wind stress, and (bottom) the buoyancy flux.

influence on the January-March average mixed layer depth and, thus, potentially on the intraseasonal variation of the SST. This thermocline depth may be associated with ENSO, as suggested by the reinforcement of the cyclonic circulation in 1999 that was linked to La Niña conditions. However, the Indian Ocean dynamics at seasonal and interannual time scales (Webster et al. 1999) will also certainly play an important role in modifying the upper-ocean structure. This relative role of the large-scale atmospheric forcing and of the internal ocean dynamics in modifying the vertical stratification of the Indian Ocean may be an important issue in explaining the interannual changes in the amplitude of the intraseasonal fluctuations of the mixed layer temperature and possibly of the atmospheric intraseasonal variability itself.

Acknowledgments. TMI data are produced by Remote Sensing Systems and sponsored, in part, by NASA's Earth Science Information Partnerships (ESIP), a federation of information sites for earth science; and by the NOAA-NASA Pathfinder program for early EOS products, principal investigator, Frank Wentz. The authors thank Gilles Reverdin who suggested investigating the drifting buoy data. The authors also want to thank the three anonymous referees who gave very useful comments on an early version of this paper.

\section{REFERENCES}

Anderson, S. P., R. A. Weller, and R. Lukas, 1996: Surface buoyancy forcing and the mixed layer of the western Pacific warm pool: Observations and ID model results. J. Climate, 9, 3056-3085.

Blanke, B., and P. Delecluse, 1993: Variability of the tropical Atlantic Ocean simulated by a general circulation model with two different mixed layer physics. J. Phys. Oceanogr., 23, 1363-1388.

Chiang, J. C. H., S. E. Zebiak, and M. A. Cane, 2001: Relative roles of elevated heating and surface temperature gradients in driving anomalous surface winds over tropical oceans. J. Atmos. Sci., 58, 1371-1394.

Chou, S.-H., C.-L. Shie, R. M. Atlas, and J. Ardizzone, 1997: Airsea fluxes retrieved from Special Sensor Microwave Imager data. J. Geophys. Res., 102, 12 705-12 726.

Ethé, C., C. Basdevant, R. Sadourny, K. S. Appu, L. Harenduprakash, P. R. Sarode, and G. Viswanathan, 2002: Air mass motion, temperature, and humidity over the Arabian Sea and western Indian Ocean during the INDOEX intensive phase, as obtained from a set of superpressure drifting balloons. J. Geophys. Res., 107, 8023, doi:10.1029/2001JD001120.

Ferreira, R. N., W. H. Schubert, and J. J. Hack, 1996: Dynamical aspects of twin tropical cyclones associated with the MaddenJulian oscillation. J. Atmos. Sci., 53, 929-945.

Fu, X., B. Wang, T. Li, and J. P. McCreary, 2003: Coupling between northward-propagating, intraseasonal oscillations and sea surface temperature in the Indian Ocean. J. Atmos. Sci., 60, 1733 1753.

Gill, A. E., 1980: Some simple solutions for heat-induced tropical circulation. Quart. J. Roy. Meteor. Soc., 106, 447-462.

Goswami, B. N., and R. S. A. Mohan, 2001: Intraseasonal oscillations and interannual variability of the Indian summer monsoon. $J$. Climate, 14, 1180-1198.

Goulet, L., and J.-Ph. Duvel, 2000: A new approach to detect and characterize intermittent atmospheric oscillations: Application to the intraseasonal oscillation. J. Atmos. Sci., 57, 2397-2416.

Harrison, D. E., and A. Vecchi, 2001: January 1999 Indian Ocean cooling event. Geophys. Res. Lett., 28, 3717-3720.

Hendon, H. H., and M. L. Salby, 1994: The life cycle of the MaddenJulian oscillation. J. Atmos. Sci., 51, 2225-2237.

Inness, P. M., and J. M. Slingo, 2003: Simulation of the MaddenJulian oscillation in a coupled general circulation model. Part I: Comparison with observations and an atmosphere-only GCM. J. Climate, 16, 345-364.

Jerlov, N. G., 1968: Optical Oceanography. Elsevier, 194 pp.

Jones, C., D. E. Waliser, and C. Gautier, 1998: The influence of the Madden-Julian oscillation on ocean surface heat fluxes and sea surface temperature. J. Climate, 11, 1057-1072.

Kawamura, R., 1988: Intraseasonal variability of sea surface temperature over the tropical western pacific. J. Meteor. Soc. Japan, 66, 1007-1012.

Kemball-Cook, S., B. Wang, and X. Fu, 2002: Simulation of the intraseasonal oscillation in the ECHAM-4 model: The impact of coupling with an ocean model. J. Atmos. Sci., 59, 1433-1453.

Köpken, C., J. N. Thépaut, G. Kelly, and A. P. Mcnally, 2001: Satellite data assimilation for numerical weather prediction. Proc. 2001 EUMETSAT Meteorological Satellite Data Users' Conf., Antalya, Turkey, EUMETSAT, 581-590. [Available from EUMETSAT, Am Kavalleriesand 31, D-64295 Darmstadt, Germany.]

Lawrence, D. M., and P. J. Webster, 2002: The boreal summer intraseasonal oscillation: Relationship between northward and eastward movement of convection. J. Atmos. Sci., 59, 1593-1606.

Levitus, S., and T. P. Boyer, 1994: Temperature. Vol. 4, World Ocean Atlas 1994, NOAA Atlas NESDIS 4, 117 pp. 
Liebmann, B., and C. A. Smith, 1996: Description of a complete (interpolated) outgoing longwave radiation dataset. Bull. Amer. Meteor. Soc., 77, 1275-1277.

Lukas, R., and E. Lindström, 1991: The mixed layer of the western equatorial Pacific Ocean. J. Geophys. Res., 96, 3343-3357.

Madden, R. A., and P. R. Julian, 1994: Observations of the 40-50day tropical oscillation-A review. Mon. Wea. Rev., 122, 814836.

Madec, G., P. Delecluse, M. Imbard, and C. Levy, 1998: OPA 8.1 Ocean General Circulation Model reference manual. Notes du pôle de modélisation, Vol. 11, Institut Pierre Simon Laplace (IPSL), Paris, France, 91 pp.

McPhaden, M. J., 1999: Genesis and evolution of the 1997-1998 El Niño. Science, 283, 950-954.

Ramanathan, V., and Coauthors, 2001: The Indian Ocean Experiment: An integrated analysis of the climate forcing and effects of the great Indo-Asian haze. J. Geophys. Res., 106 (D22), 28 371-28 398.

Rao, R. R., R. L. Molinari, and J. F. Festa, 1989: Evolution of the climatological near-surface thermal structure of the tropical Indian Ocean. 1. Description of mean monthly mixed layer depth, and sea surface temperature, surface current, and surface meteorological fields. J. Geophys. Res., 94 (C8), 10 801-10 815.

Redelsperger, J.-L., F. Guichard, and S. Mondon, 2000: A parameterization of mesoscale enhancement of surface fluxes for largescale models. J. Climate, 13, 402-421.

Reverdin, G., D. Cadet, and D. Gutzler, 1986: Interannual displacements of convection and surface circulation over the equatorial Indian Ocean. Quart. J. Roy. Meteor. Soc., 112, 43-67.

Reynolds, R. W., and T. M. Smith, 1994: Improved global sea surface temperature analyses using optimum interpolation. J. Climate, 7, 929-948.

Schiller, A., and J. S. Godfrey, 2003: Indian Ocean intraseasonal variability in an ocean general circulation model. J. Climate, 16, 21-39.

Sengupta, D., and M. Ravichandran, 2001: Oscillations of Bay of Bengal sea surface temperature during the 1998 summer monsoon. Geophys. Res. Lett., 28, 2033-2036.

— B. B. Goswami, and R. Senan, 2001: Coherent intraseasonal oscillations of ocean and atmosphere during the Asian summer monsoon. Geophys. Res. Lett., 28, 4127-4130.

Shinoda, T., and H. H. Hendon, 1998: Mixed layer modeling of intraseasonal variability in the tropical western Pacific and Indian Oceans. J. Climate, 11, 2668-2685.

- and - 2001: Upper-ocean heat budget in response to the Madden-Julian oscillation in the western equatorial Pacific. $J$. Climate, 14, 4147-4165.

,$- \ldots$, and J. Glick, 1998: Intraseasonal variability of surface fluxes and sea surface temperature in the tropical western Pacific and Indian Oceans. J. Climate, 11, 1685-1702.

Simmons, A. J., 2001: Development of the ERA-40 data-assimilation system. ERA-40 Project Rep. Series, No. 3, ECMWF, 20 pp.

Uppala, S., 2001: ECMWF Reanalysis 1957-2001, ERA-40. ERA40 Project Rep. Series, No. 3, ECMWF, 10 pp.

Vialard, J., and P. Delecluse, 1998: An OGCM study for the TOGA decade. Part I: Role of salinity in the physics of the western Pacific fresh pool. J. Phys. Oceanogr., 28, 1071-1088.

_- C. Menkes, J.-P. Boulanger, P. Delecluse, E. Guilyardi, and M. McPhaden, 2001: A model study of the oceanic mechanisms affecting the equatorial SST during the 1997-98 El Niño. J. Phys. Oceanogr., 31, 1649-1675.

Waliser, D. E., K. M. Lau, and J.-H. Kim, 1999: The influence of coupled sea surface temperatures on the Madden-Julian oscillation: A model perturbation experiment. J. Atmos. Sci., 56, 333358.

Wang, B., and T. Li, 1994: Convective interaction with boundarylayer dynamics in the development of a tropical intraseasonal system. J. Atmos. Sci., 51, 1386-1400.

_- , and X. Xie, 1998: Coupled modes of the warm pool climate system. Part I: The role of air-sea interaction in maintaining Madden-Julian oscillation. J. Climate, 11, 2116-2135.

Webster, P. J., V. O. Magana, T. N. Palmer, J. Shukla, R. A. Tomas, M. Yanai, and T. Yasunari, 1998: Monsoons: Processes, predictability, and the prospects for prediction. J. Geophys. Res., 103 (C7), 14 451-14 510.

_- A. M. Moore, J. P. Loschnigg, and R. Leben, 1999: Coupled ocean-atmosphere dynamics in the Indian Ocean during 1997 98. Nature, 401, 356-360.

Weller, R. A., and S. P. Anderson, 1996: Surface meteorology and air-sea fluxes in the western equatorial Pacific warm pool during the TOGA Coupled Ocean-Atmosphere Response Experiment. J. Climate, 9, 1959-1992.

Wentz, F. J., C. Gentemann, D. Smith, and D. Chelton, 2000: Satellite measurements of sea-surface temperature through clouds. Science, 288, 847-850.

Woolnough, S. J., J. M. Slingo, and B. J. Hoskins, 2000: The relationship between convection and sea surface temperature on intraseasonal timescales. J. Climate, 13, 2086-2104.

,$- \ldots$, and _ -2001 : The organization of tropical convection by intraseasonal sea surface temperature anomalies. Quart. J. Roy. Meteor. Soc., 127, 887-907.

Zhang, C., and M. J. McPhaden, 2000: Intraseasonal surface cooling in the equatorial western Pacific. J. Climate, 13, 2261-2276.

, H. H. Hendon, W. S. Kessler, and A. J. Rosati, 2001: A workshop on the MJO and ENSO. Bull. Amer. Meteor. Soc., 82, 971976. 